\title{
Character morality, enjoyment, and appreciation: A replication of Eden, Daalmans, and Johnson (2017)
}

\author{
Koji Yoshimura \\ West Virginia University, ky0018@mix.wvu.edu
}

Follow this and additional works at: https://researchrepository.wvu.edu/etd

Part of the Mass Communication Commons

\section{Recommended Citation}

Yoshimura, Koji, "Character morality, enjoyment, and appreciation: A replication of Eden, Daalmans, and Johnson (2017)" (2019). Graduate Theses, Dissertations, and Problem Reports. 4107.

https://researchrepository.wvu.edu/etd/4107

This Thesis is protected by copyright and/or related rights. It has been brought to you by the The Research Repository @ WVU with permission from the rights-holder(s). You are free to use this Thesis in any way that is permitted by the copyright and related rights legislation that applies to your use. For other uses you must obtain permission from the rights-holder(s) directly, unless additional rights are indicated by a Creative Commons license in the record and/ or on the work itself. This Thesis has been accepted for inclusion in WVU Graduate Theses, Dissertations, and Problem Reports collection by an authorized administrator of The Research Repository @ WVU. For more information, please contact researchrepository@mail.wvu.edu. 
Character morality, enjoyment, and appreciation:

A replication of Eden, Daalmans, and Johnson (2017)

\section{Koji Yoshimura}

Thesis submitted

to the Eberly College of Arts and Sciences

At West Virginia University

In partial fulfillment of the requirements for the degree of

Master of Arts in

Communication Theory and Research

Nicholas D. Bowman, Ph.D., Chair

Jaime Banks, Ph.D.

Elizabeth L. Cohen, Ph.D.

Department of Communication Studies

Morgantown, West Virginia

2019

Keywords: morally ambiguous characters, entertainment theory, affective disposition theory, replication

Copyright 2019 


\begin{abstract}
Character morality, enjoyment, and appreciation:

A replication of Eden, Daalmans, and Johnson (2017)
\end{abstract}

Koji Yoshimura

Much research on media entertainment seeks to explain why viewers enjoy and appreciate a variety of media content. Affective disposition theory suggests that media enjoyment results from perceptions of the morality of characters and viewers' expectations for characters' narrative outcomes. However, research has struggled to explain how characters with varying morality (i.e., not perfectly good or bad) entertain viewers. This study replicates a previous study conducted by Eden, Daalmans, and Johnson (2017) that investigated different types of morally ambiguous characters, using a typology of character types based on an online, collaboratively sourced typology.

Like the original study, this study found that character types varied in morality across moral domains, and that MACs were not more associated with variables related to self. However, unlike the original study, the present study found that morality was not significantly related to enjoyment or appreciation. Rather, according to the replicated analyses, value homophily was found to be significantly related to enjoyment, and both value homophily and self-expansion were significantly related to appreciation.

Additionally, after collapsing the self-expansion, wishful identification, value homophily, and IOS variables into a single aggregate variable, the new combined variable was significantly related to both enjoyment and appreciation.

The results of this study suggest that media viewers do not make very nuanced moral evaluations of media characters. Character types including heroes, villains, and different types of MACs were often not significantly different from one another in terms of perceived moral upholding. This may be explained by the schemas that viewers access, which guide their affective dispositions and moral disengagement. Implications for entertainment media research and are discussed. 


\section{Acknowledgements}

First and foremost, I would like to acknowledge my advisor, Dr. Bowman for everything that he did to help me complete this thesis. This project could not have been possible without his guidance, patience, care and insight. Thank you for always pushing me to do better.

I thank my committee members, Dr. Cohen and Dr. Banks, for their time and effort, for their wonderful advice, and for their flexibility and supportiveness.

I must acknowledge and thank Dr. Eden, Dr. Daalmans, and Dr. Johnson, not only for the wonderful research on which this thesis is based, but also for their enthusiasm, assistance, advice, and encouragement.

I would like to thank Dr. Rittenour for allowing me to come to West Virginia University for my M.A. studies, and for her unwavering positivity and support throughout my time in the program.

I also thank Aaron, Anna, Ashleigh, Brenna, Emma, Erin, Matt, and Molly for helping me survive this past year of grad school. I appreciate all of the moral support, late night conversations, and wonderful experiences. Part of the ship, part of the crew.

Finally, I would like to thank Dr. Rendleman of Seattle Pacific University, who taught me to love film, inspired my interest in media research, and motivated me to pursue graduate school. 


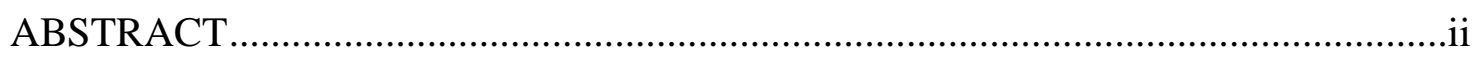

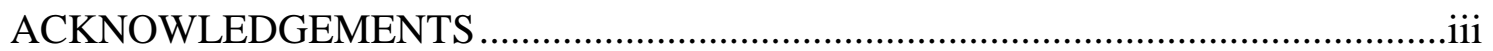

TABLE OF CONTENTS ................................................................................

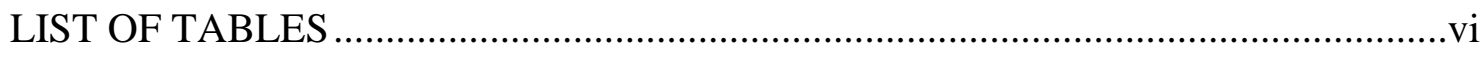

LIST OF FIGURES ....................................................................................... vii

CHAPTER I: INTRODUCTION ....................................................................

Affective Disposition Theory (ADT) ..........................................................2

Overview and Mechanics of ADT ....................................................2

Overview of Research on ADT ......................................................... 3

ADT and Schemas ..................................................................

Enjoyment and Appreciation in ADT ..............................................6

Morally Ambiguous Characters ..................................................................... 7

Summary of Eden et al. (2017) .............................................................

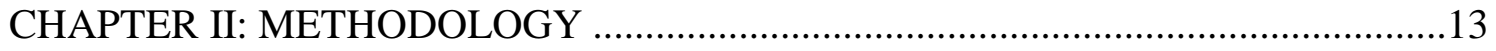

Participants..................................................................................... 14

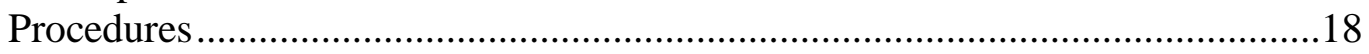

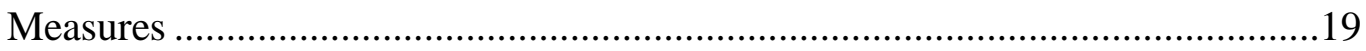

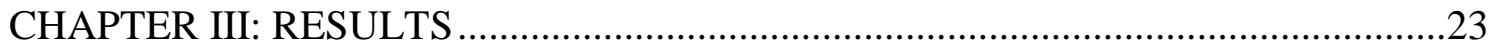

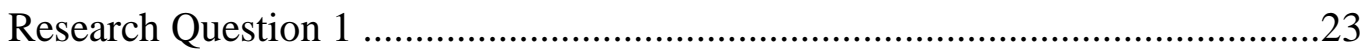

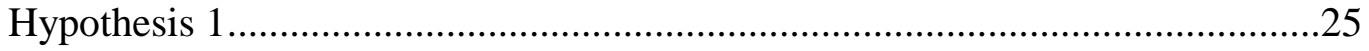

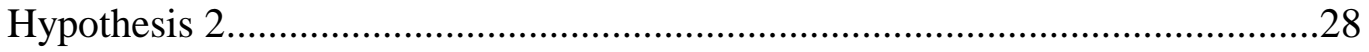

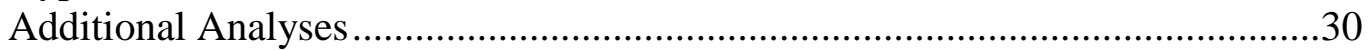

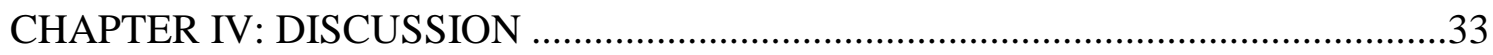

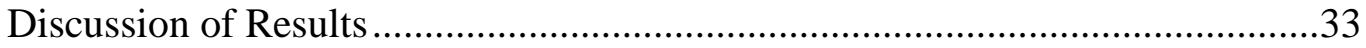

Limitations and Future Research Directions................................................41

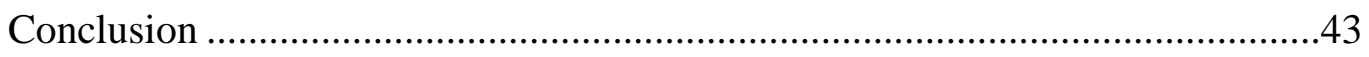

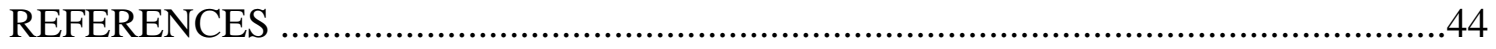

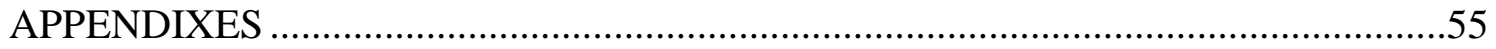


Appendix A: Character Trope Descriptions

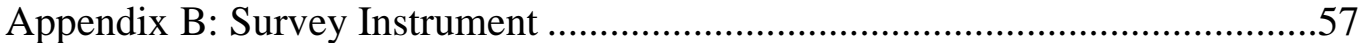




\section{List of Tables}

$\underline{\text { Page }}$

Table 1. Participant's individual morality score means and comparison. .15

Table 2. Correlations between all study variables. .22

Table 3. Means of moral upholding scores for each moral foundation, by condition. ....25

Table 4. Means of self-related variable responses, by condition.

Table 5. Regression results for enjoyment and appreciation.

Table 6. Regression results for enjoyment and appreciation with collapsed self variable.

Table 7. Regression results with dummy coded tropes. 


\section{List of Figures}

$\underline{\text { Page }}$

Figure 1. Moral upholding composites, by character condition.

Figure 2. Self-related variable composites, by character condition.............................27 
Character morality, enjoyment, and appreciation:

A replication of Eden, Daalmans, and Johnson (2017)

In recent years, a growing body of media effects research has examined hedonic and eudaimonic gratifications for media use, or in other words, how viewers enjoy and appreciate media (see Vorderer \& Reinecke, 2015). One frequently used theoretical approach in such inquiries is affective disposition theory (ADT; Zillmann, 2000; Zillmann \& Cantor, 1976), which explains that enjoyment is facilitated by viewers perceptions of the morality of characters in media. At a foundational level, ADT proposes that morally good characters will be liked and bad characters disliked (Zillmann \& Cantor, 1976). Recent research has investigated the impact of characters who display different levels of morality, including pure heroes and villains (e.g., Eden, Oliver, Tamborini, Limperos, \& Woolley, 2015; Grizzard, Huang, Fitzgerald, Ahn, \& Chu, 2017), and morally ambiguous characters, or MACs (see Kleemans, Eden, Daalmans, van Ommen, \& Weijers, 2017; Krakowiak, 2015; Tamborini et al., 2018). The prevalence and apparent popularity of MACs (Daalmans, Hijmans, \& Wester, 2013) indicates that viewers do, in fact, like and enjoy them despite their imperfect morality. This phenomenon is seemingly counter to how ADT argues that viewer enjoyment should operate — simply put, characters that are not clearly "good" or "bad" should be more difficult to enjoy—and therefore MACs present a challenge for the straightforward predictions of ADT (Raney, 2004).

In response to this apparent contradiction, researchers have attempted to reveal mechanisms underlying viewers' enjoyment of MACs (see Kleemans et al., 2017). In one such study, Eden, Daalmans, \& Johnson (2017) investigated how different character 
types, including MACs, are related to enjoyment and appreciation, using a typology of characters from the popular culture website tvtropes.com. Eden et al. proposed that viewers' apparent positive reactions to media featuring MACs were indicative of appreciation rather than hedonic enjoyment, but the results of their study did not find that character type (i.e., heroes, villains, and MACs) was significantly related to enjoyment or appreciation. While character type did not seem to relate to enjoyment or appreciation, Eden et al.'s results indicated that morality is associated with enjoyment, while selfexpansion more strongly related to appreciation. This suggests that there may be truth to their argument that people might appreciate MACs. The present study is an attempt to replicate the original study of Eden et al. (2017) in order to validate the original findings, which did not fully support the original authors' theory-based predictions, and to contribute to explaining why and how viewers are entertained by MACs.

\section{Affective Disposition Theory (ADT)}

Overview and mechanics of ADT. Affective disposition theory is a theory of mass communication that explains that media enjoyment takes place through viewers' perceptions of media characters (see Raney, 2004, 2006; Zillmann, 2000). According to ADT, media viewers continually judge the morality of a character's actions (Zillmann, 2000), and use those judgments to form affective dispositions (Raney, 2004). The process of enjoyment is theorized to be facilitated by these affective dispositions and the character's narrative outcomes (Raney, 2004; Zillmann, 2000; Zillmann \& Cantor, 1977). Specifically, viewers will develop expectations for a character's future outcomes, and the alignment between the viewer's expectations and the character's actual outcomes is theorized to cause the experience of enjoyment (Raney, 2004; Raney \& Bryant, 2002). In 
other words, ADT predicts that viewers will enjoy watching characters who engage in good moral actions (or those whose actions are congruent with the viewer's moral values) be rewarded, and seeing characters who engage in bad moral actions (or those whose actions violate the viewer's moral values) be punished (Zillmann, 2000). Conversely stated, audiences will likely not enjoy, and may even be upset by, watching good characters be punished or bad characters be rewarded.

Overview of research on ADT. Theories of media enjoyment based on affective dispositions were initially developed by Dolf Zillmann and his colleagues, who first used the concepts of ADT to investigate people's enjoyment of disparaging humor (Zillmann \& Cantor, 1972). Over a period of nearly 50 years, entertainment scholars have applied ADT to study a host of media-enjoyment phenomena. For example, Hoffner and Cantor (1991) utilized ADT to examine children's responses to frightful/suspenseful media, and found that the influence of affect toward the character on enjoyment is related to the age of the child. Zillmann, Taylor, and Lewis (1998) investigated the enjoyment of and reactions to positive and negative news reports, finding that viewers' affective dispositions toward the subject of a news report influenced their enjoyment responses. More recently, the results of Kinnally, Tuzunkan, Raney, Fitzgerald, \& Smith (2013) supported the relationships between schemas and affective disposition formation with sports figures in media, and Weinmann et al. (2017) found evidence that affective dispositions influence information processing and judgment in a study involving perceptions of political talk shows. Across many types of media content, research involving ADT continues to support its foundational mechanisms.

ADT and schemas. Zillmann (2000) argued that viewers act as "untiring moral 
monitors" (p. 54), in that they continuously assess characters' actions and form affective dispositions accordingly. However, Zillmann's research involving ADT suggests that he was not concerned about the initial source of affective dispositions. Having observed that viewers often form affective dispositions quickly and with little moral assessment, Raney (2004) proposed an alternate explanation that viewers use schemas to guide their perceptions of media to address this gap. The term "schemas" refers to cognitive frameworks that constitute one's understanding of a stimulus, and influence perceptions and interpretations of similar or related stimuli (Raney, 2004). The notion of schemas is conceptually similar to that of mental models (e.g., Johnson-Laird, 1983), however mental models are not discussed in the literature surrounding schemas. Raney (2004) argued that the range of affective responses to individual characters is likely to be limited by the lens of the schema by which they are interpreted. In other words, he argues that viewers will quickly form affective dispositions with characters that require little or no moral consideration, and these initial affective dispositions will affect how characters are subsequently interpreted. Furthermore, he proposed that viewers are inclined to maintain their sense of enjoyment, therefore, through a process known as moral disengagement (cf., Bandura, 1986), schema-directed enjoyment of characters will influence viewers moral judgements of characters, such that viewers will be more likely to excuse immoral behavior committed by a liked character.

Based on the ideas that viewers interpret media through schemas and may morally disengage in order to preserve enjoyment, Raney (2004) offered two formalized propositions extending ADT. First, he proposed that "the initial formation of an affective disposition toward a character may at times precede specific moral evaluations of the 
character" (p. 361). Thus, viewers encounter characters through cognitive schemas, which facilitate the formation of their affective dispositions before the viewer actually evaluates the character's morality through observing their actions. Raney suggests that this may even take place before characters appear on screen, as narrative elements might activate schema which could prime viewers' perceptions. Second, Raney (2004) proposed that "because viewers expect that liked characters will do good things and disliked characters will do bad things, those expectations lead viewers to interpret character actions and motivations in line with the established dispositional valences rather than to morally scrutinize each action and motivation" (p. 361). In other words, a character's actions will be judged according to the viewer's affective dispositions; whether a character's actions are justified or condemned will be determined by whether the action is congruent with the viewer's established disposition toward the character. Raney (2004) argues that this occurs because viewers desire to experience enjoyment from media, and in the interest of doing so they attempt to maintain their held disposition toward a character, such that they may discount or misattribute that character's moral behavior. Raney referred to this process as "moral disengagement", borrowing the term from Bandura (1986), who argued that individuals may selectively apply personal moral codes depending on the situation.

Raney's (2004) two propositions have seen received some empirical support. For example, the results of Shafer and Raney (2012) provided evidence that viewers form and use schemas to guide their perceptions of anti-hero driven narratives. More recently, Grizzard et al. (2017) identified that content elements, such as visual cues and opposing characters, influence the activation and use of schemas in viewers' moral judgments of 
characters. The concept of moral disengagement has also been generally supported in studies of character morality (e.g., Janicke \& Raney, 2015, Krakowiak \& Tsay-Vogel, 2013, 2015; Sanders \& Tsay-Vogel, 2016; Tsay \& Krakowiak, 2011; Tsay-Vogel \& Krakowiak, 2016). For example, Tsay-Vogel \& Krakowiak (2016) found evidence supporting moral disengagement's facilitating effect on enjoyment, leading them to suggest that "rationalizing bad behaviors is a necessary condition for enjoyment to occur" (p. 58). In the present study, Raney's (2004) two propositions are especially salient to the understanding of morally ambiguous characters, who may participate in both good and bad moral behavior.

Enjoyment and Appreciation in ADT. Early ADT-based research utilized the term “appreciation” (e.g., Zillmann \& Bryant, 1975; Zillmann \& Cantor, 1977) to refer to liking or pleasure associated with viewing media (Raney, 2006), however now the term "enjoyment" is primarily used to refer to hedonic (i.e., pleasurable) gratifications, while the term "appreciation" is typically reserved for eudaimonic (i.e., meaningful) gratifications (see Oliver, 2008; Oliver \& Bartsch, 2010; Oliver \& Raney, 2011). Raney (2004) conceptualized media enjoyment succinctly as "the sense of pleasure that one derives from consuming media products" (pp. 348-349). In the present study, it is important to note that while ADT's explanatory power does not necessarily extend beyond enjoyment, the Eden et al. (2017) proposed that MACs may be more closely associated with appreciation than enjoyment responses, as appreciation is thought to be related to self-reflective processes that moral ambiguity may foster through processes such as self-expansion (see Slater, Johnson, Cohen, Comello, \& Ewoldsen, 2014). 


\section{Morally Ambiguous Characters (MACs)}

ADT broadly explains enjoyment as a function of characters' morality and outcomes, and thus should be most effective when applied to characters possessing clearly defined good or bad moral natures. However, as noted by Eden et al. (2017), the moral nature of fictional characters is typically not explicitly defined or dichotomously presented. Research has indicated that morally ambiguous characters (MACs) have become more prevalent in entertainment media over time (Daalmans, Hijmans, \& Wester, 2013), and that they are enjoyed despite their imperfect moral conduct (Krakowiak \& Oliver, 2012; Krakowiak \& Tsay, 2011; Krakowiak \& Tsay-Vogel, 2013, 2015; Tsay \& Krakowiak, 2011). Due to the nature of MACs, it is more challenging to explain why they are enjoyed from the perspective of ADT. Consequently, there has been much attention to resolving this apparent contradiction between character morality and the enjoyment processes outlined by ADT among media scholars (Grizzard et al., 2019).

Scholars have proposed multiple ways to account for potential variance among specific MACs. For example, Eden et al. (2017) utilized a typology of moral character tropes derived from tvtropes.com, and Tamborini et al. (2018) recently tested a fivecategory typology based on the model of intuitive morality and exemplars (MIME; Tamborini, 2013), in which types range from completely morally good, to neutral, to completely morally bad, across all domains of morality. Indeed, one of the core contributions of Eden et al. (2017) was evidence supporting the notion that types of MACs vary significantly in their perceived morality across all moral domains.

Importantly, researchers have noted that the term "morally ambiguous character" itself is lacking a unifying definition (Kleemans, et al., 2017; Tamborini et al., 2018). 
MACs are often described by what they are not: purely good or bad (e.g., Krakowiak \& Tsay-Vogel, 2015). It is usually suggested that MACs are those characters who engage in both good and bad moral actions (Krakowiak \& Oliver, 2012; Krakowiak \& Tsay, 2011; Krakowiak \& Tsay-Vogel, 2013, 2015; Tsay \& Krakowiak, 2011; Tsay-Vogel \& Krakowiak, 2016), or those who enact both prosocial and antisocial behaviors (Krakowiak \& Oliver, 2012; Tsay-Vogel \& Krakowiak, 2016). Additionally, the consistency of characters' moral actions has also been argued to be an important defining factor (Eden, Grizzard, \& Lewis, 2011; Kleemans et al., 2017; Tamborini et al., 2010), and some have suggested that there are traits that viewers may use to identify MACs, such as their physical appearance or aggression (e.g., Grizzard et al., 2017; Krakowiak, 2015).

Researchers generally agree that the term "hero" denotes characters whose motivations and actions are completely good, while "villain" is reserved for characters whose motivations and actions are completely bad (Kleemans et al., 2017; Tamborini et al., 2018). Any character that falls between those two poles can be considered a morally ambiguous character (Krakowiak \& Oliver, 2012). One reason for confusion is that researchers have studied different conceptualizations of MACs depending on the scope of their study (see Kleemans et al., 2017; Krakowiak, 2015; Tamborini et al., 2018). For example, a source of confusion may be that certain terms such as "morally ambivalent character" (e.g. Daalmans, Hijmans, \& Wester, 2017) or “neutral character” (e.g., Tamborini et al., 2010) have been used to refer to the same type of character defined by "morally ambiguous character" who engages in both good and bad moral behavior. In addition, some research has centered on specific prototypical examples of MACs (e.g., 
Janicke \& Raney, 2015; Tsay-Vogel \& Krakowiak, 2016; van Ommen, Daalmans, \& Weijers, 2014), while other studies examine MACs broadly (e.g., Eden et al., 2017; Krakowiak \& Tsay-Vogel, 2013).

Yet another term used in research is "anti-hero," which has been defined as a character featuring good motivations but possessing notable flaws (Janicke \& Raney, 2015). In popular culture, "anti-hero" typically refers to those characters who serve the role of the protagonist, but who lack conventional heroic qualities or attributes. Antiheroes are also differentiated by the importance of character development; anti-heroes are assumed to evolve over the course of a narrative (e.g., Janicke \& Raney, 2015). Based on the character tropes used by Eden et al. (2017), it is apparent that there is a great deal of overlap between anti-heroes and MACs, highlighting the importance of clearly distinguishing the two terms. Therefore, because antiheroes are characterized by imperfect moral conduct (Shafer \& Raney, 2012), anti-heroes can be considered a type of MAC, while not all MACs are necessarily anti-heroes. Therefore, "morally ambiguous character" is a superordinate term that encompasses all characters whose morality is not completely good or bad.

\section{Summary of Eden et al. (2017)}

The original study by Eden et al. (2017) examined responses to perceptions of common character types, or tropes, sources from tvtropes.org, a wiki site devoted to television and popular culture. Eden et al. noted that fictional characters in entertainment media can be complex and idiosyncratic (Eden et al., 2015), and so they sought to investigate responses to a variety of characters. Although not theoretically based, the fact that wiki pages like TV Tropes are collectively curated was taken to suggest some 
potential validity to the typology (Eden et al., 2017). Also, the character tropes may represent schemas, as suggested by Raney (2004). The tropes used by Eden et al. were: hero, Disney anti-hero, pragmatic anti-hero, classical anti-hero, unscrupulous hero, nominal hero, and villain.

The original study was conducted via a survey with random assignment to one of seven trope conditions. The participants were asked to think of a fictional character that fit the description of their randomly assigned trope, and then to briefly describe their character choice and explain why that character suited the trope. Then, participants completed a questionnaire evaluating perceived self-expansion, wishful identification, value homophily, inclusion of other in self (IOS), enjoyment, and appreciation with that character in mind.

The first goal of Eden et al. (2017) was to explore whether morally ambiguous characters vary along a continuum of morality (i.e., ranging in overall morality from good to bad) or if they vary among separate dimensions of morality, such as the moral domains of moral foundations theory (MFT; Haidt \& Joseph, 2007). Consistent with previous media research exploring character perceptions (e.g., Eden et al., 2015; Eden \& Tamborini, 2017; Grizzard et al., 2017; Kleemans et al., 2017), morality in the original study was conceptualized according to MFT. MFT characterizes the process of moral judgement as rapid and intuitive, occurring without conscious awareness; moral judgments are thus referred to as "moral intuitions." MFT proposes that morality can be upheld or violated in specific dimensions (called moral domains), namely: care, fairness, loyalty, authority, and purity. While past research suggested that character types (i.e., types of MACs) may vary among individual moral domains (e.g., Eden et al., 2015), 
Eden et al. (2017) found no significant differences in terms of the individual moral domains participants expected to be violated by characters of different types. However, they did observe significant differences according to character type across all five dimensions of morality, except for the classical anti-hero type, which was not significantly different from the hero type. By ordering the classical anti-hero type directly after the hero type along the TV Tropes proposed continuum from hero to villain, they observed that the seven tropes followed linear trends for each moral domain, forming a continuum of morality ranging in terms of perceived moral violation. The authors forwarded this finding as evidence to suggest that "MACs may be best considered as variations along a continuum of morality ranging from very good to very bad" (Eden et al., 2017, p. 13). While evidence from their study points to this conclusion, Eden et al. qualified that it may be the case that this outcome was a result of the specific trope typology used, and that variation among individual dimensions of morality may still better explain perceptions of character morality than variation in overall morality. Their original article acknowledged that the TV Tropes typology that was used was ordered according to factors beyond perceived morality alone. Therefore, it is important to consider whether Eden et al.'s finding theoretically supported their proposal of a continuum of character types ranging from least to most morally violating. The current replication study should lend itself to providing more clarity on this phenomenon.

The second goal of the original study was to examine associations between character types and variables related to the self. As previously described, ADT struggles to explain why audiences respond positively to MACs, since imperfect and/or complex morality complicates the proposition that viewers enjoy seeing good characters be 
rewarded and bad characters punished. In addition to the hedonic enjoyment that ADT seeks to explain, scholars have proposed appreciation (i.e., eudaimonia) as another outcome of media exposure (e.g., Oliver, 2008; Oliver \& Raney, 2011). Appreciation is linked to meaningful media experiences (Lewis, Tamborini, \& Weber, 2014; Oliver \& Bartsch, 2010), and research indicates that it involves the viewers' self-concept (e.g., Wirth, Hofer, \& Schramm, 2012). Eden et al. (2017) predicted that MACs would be more closely associated with self-related variables (and therefore appreciation), than heroes and villains, who they suggested would be more strongly associated with moral concerns. Based on the temporarily expanded boundaries of the self model (TEBOTS; Slater et al., 2014), which proposes that people expand their self-concept through vicarious experiences with characters, Eden et al. (2017) posited that variations in morality between different character types may allow for more or less self-expansion. In other words, viewers may expand their sense of self by through vicarious experience with characters whose morality is different from their own. They also examined perceptions of wishful identification, value homophily, and inclusion of other in self (IOS; Aron, Aron, \& Smollan, 1992). Eden et al.'s results, however, did not find that MACs were more strongly related to any of the self-related variables than heroes or villains.

The third goal of the original study was to explore how character tropes would be differentially associated with enjoyment and appreciation. Following the same logic as the rationale for the self-related variables, Eden et al. (2017) predicted that MACs would be more strongly associated with appreciation, and heroes and villains with enjoyment. Character type was not found to be significantly associated with either enjoyment or appreciation when accounting for all variables (i.e., perceived morality and self-related 
variables). However, self-expansion, wishful identification, and moral violation were related to enjoyment. Similarly, self-expansion and wishful identification were related to appreciation, but moral violation had no relation to appreciation.

Given the theoretical and empirical foundations laid out by Eden et al. (2017), it was fascinating that character type did not seem to vary among individual moral domains, and that the hypotheses were unsupported. Therefore, this study sought to replicate Eden et al.'s study in an attempt to support or enhance current knowledge on MACs in entertainment effects research. As such, the original research question and hypotheses from Eden et al. (2017) were retained in the present study.

RQ1: Do MACs, as defined by the character tropes provided in popular media culture, exhibit variable morality based on specific moral dimensions demonstrated in previous research?

H1: MACs will be associated with greater self-expansion, wishful identification, homophily, and IOS than heroes or villains.

H2: Character type will be differentially associated with enjoyment versus appreciation responses to characters, such that MACs will be more strongly associated with appreciation, and heroes and villains with enjoyment.

\section{Method}

The original authors were consulted in order to perform an accurate replication of Eden et al.'s (2017) methodology. They shared the original survey instruments (A. Eden, personal communication, January 14, 2019), which were reverted/translated to English (from Dutch) for use in the present study. First, the original questionnaire was translated via Google translate. Then, individual scales within the questionnaire were identified and 
compared with example items found in the scales' original sources, in order to ensure the correct wording of the items was maintained. Some scales that were included in the original survey were not used in the final publication by Eden et al. (2017), and were therefore omitted from primary analysis in the present study. These scales included the participants' individual moral foundation questionnaire (adapted MFQ-30; see Graham, Nosek, Haidt, Iyer, Koleva, \& Ditto, 2011), items measuring participants’ film and television use patterns, and media content preferences. Study materials including survey materials, anonymized versions of the datasets, and SPSS output files from this study are available through the Open Science Framework (OSF) space for this project: https://osf.io/kqb5h/.

\section{Participants}

While the original study used a Dutch sample recruited through a market research firm $(N=294)$, participants in the present study are students recruited from a large, midAtlantic university in the United States. The use of a US student sample allowed for variation between the two samples, permitting comparison of the predicted effects.

Specifically, significant differences in the individual moral foundation scores between the two samples (described in detail below), suggested that the replicated findings in the present study may be generalizable to broader populations.

Relevant to the present study, morality is often considered to be linked to culture. Indeed, research on MFT suggests that culture may influence the degree to which specific moral dimensions are upheld or violated (Haidt \& Joseph, 2007). Therefore, it is important to consider cultural differences between the United States and the Netherlands.

Using data from both the original study (Eden et al., 2017) and the present study, 
participants reports of their own moral views were compared. Participants in both studies were asked to complete a (shortened) version of the moral foundations questionnaire (MFQ-30; Graham et al., 2011). See Table 1 for means, standard deviations, and $t$-test comparison results for participants' moral domain scores.

Table 1. Participant's individual morality score means and comparison.

\begin{tabular}{lccc}
\hline & $\begin{array}{c}\text { Eden et al. } \\
(2017)\end{array}$ & Current Study & $t$-test results \\
& $M(S D)$ & $M(S D)$ & \\
& $(n=294)$ & $(n=244)$ & \\
\hline Care & $5.05(1.15)$ & $5.32(1.22)$ & $t(536)=2.637, p=.0086$, Cohen's $d=.23$ \\
Fairness & $4.99(1.14)$ & $5.31(1.19)$ & $t(536)=3.177, p=.0016$, Cohen's $d=.27$ \\
Loyalty & $4.47(1.15)$ & $4.80(1.15)$ & $t(536)=3.314, p=.0010$, Cohen's $d=.29$ \\
Authority & $4.38(1.13)$ & $4.47(1.13)$ & $t(536)=.920, p=.3581$, Cohen's $d=.08$ \\
Purity & $4.37(1.19)$ & $4.14(1.29)$ & $t(536)=-2.148, p=.0321$, Cohen's $d=.19$ \\
\hline
\end{tabular}

The American student sample surveyed in the present study reported higher means than the original Dutch sample for all moral domains except for purity. American culture tends to emphasize loyalty and authority; therefore, it is not surprising that means reported for those moral domains would be higher than the Dutch sample (it should also be noted that the means for the authority domain were not statistically significant). Political ideology has also been linked with the salience of individual moral domains (Graham et al., 2011). Politically, while the United States prides itself on democratic principles, the Netherlands ranks higher on the Economist Intelligence Unit's democracy index, sitting at number ten to the United States' twenty-four (The Economist Intelligence Unit, 2019). Additionally, the Social Progress Index, which assesses and ranks countries according to citizens' social welfare, ranked the Netherlands at number seven in 2018, while the United States was ranked at number twenty-five (Social 
Progress Imperative, 2018). Therefore, it is surprising that the means for the care and fairness domains were higher for the American student sample than for the original Dutch sample, since those moral domains have been suggested to be related to more progressive/collectivistic ideology. However, keeping in mind that higher education and college student populations tend to be associated with liberalism (see Jaschik, 2017), these results may be less surprising. Religion is also considered to be indicative of morality (e.g., Tamborini, Eden, Bowman, Grizzard, Lachlan, 2012), and linked to the moral domain of purity (Haidt \& Joseph, 2007). The Netherlands has a higher concentration of non-religious people, with $50.1 \%$ of Dutch people identified as not religiously affiliated in 2015 (Schmeets, 2016), compared to only 18.2\% of Americans in 2016 (Newport, 2016). Therefore, the finding that the American student sample rated significantly lower on purity is unsurprising.

Altogether then, there are reasons to believe that U.S. and Dutch populations may differ in their cultural values, which may result in distinctions in their perceptions of morality. This suggests that those results of the present study which replicated the findings of the original study did so despite such differences, implying that the results replicated in this study may be generalizable across populations.

An American young-adult population was expected to be an effective comparison for the present study due to the similarities between Dutch and American media consumption. For example, in 2018 nine of the top ten highest grossing films in the Netherlands were American products, and seven of those same films (Aquaman, Avengers: Infinity War, Black Panther, Bohemian Rhapsody, Incredibles 2, Jurassic World: Fallen Kingdom, Mission: Impossible - Fallout) were also among the top ten 
highest grossing films in the United States (Boxofficemojo.com). In addition, Eden et al.'s (2017) original study found that in six of the seven character type categories, the most frequently selected character was from an American (US) product. Therefore, because it would seem to be that Dutch viewers roughly consume the same media content as American audiences, it is expected that their evaluation of fictional characters will be based around the same or similar schema structures that Raney (2004) argued guide interpretation. Furthermore, in terms of assessing morality of characters, Eden and Tamborini (2017) suggested that student samples should not differ significantly from other populations. Additionally, Grizzard et al. (2019) tested the validity of the extended character morality questionnaire (used to assess morality in the present study) across both student and non-student samples.

While convenience sampling is considered a limitation and a challenge to generalizability, it does not severely diminish the value of the present study. As noted by McEwan, Carpenter, and Westerman (2018), convenience sampling can be less of a concern in replication studies if research is conducted across varied samples, which could account for sampling error through repeated null hypothesis testing. Replicating research among different populations can also provide support for the external validity of the findings and therefore enhance generalizability (Shadish, Cook, \& Campbell, 2002).

In the original article, Eden et al. (2017) reported the effect size of Roy's largest root $=.42$, for the results of their first research question. An initial power analysis (G*power; Faul, Erdfelder, Lang, \& Buchner, 2007; Faul, Erdfelder, Buchner, \& Lang, 2009) based on this effect size indicated that a minimum of 84 participants should be sufficient for statistical power (due to the anticipated attrition rate associate with online 
survey data, the target sample size was initially set at 170 participants, or about twice the required sample). However, G*power analysis for MANOVA uses Pillai's Trace, which could not be translated from Roy's largest root. Reanalysis of the original study data yielded a value for Pillai's Trace of .385. Therefore, the power analyses were replicated using this value, based on 7 groups (trope conditions) and 5 response variables (moral domains), $\alpha=.05,0.95$ power. The replicated power analysis indicated that a sample of 91 participants would be sufficient for statistical power (based on the most conservative effect size).

In total, $N=244$ participants participated in the present study, recruited broadly from a campus-wide email at West Virginia University. ${ }^{1}$ The participants ranged from 18 to 58 years of age $(\mathrm{M}=21.79 ; \mathrm{SD}=5.42)$. Participants' self-reported gender (openended question) included 167 women (68.4\%) and 77 men (31.6\%). All study procedures were approved by the university's institutional review board.

\section{Procedures}

Following the procedure used by Eden et al. (2017), participants were randomly assigned to one of the seven character trope conditions and asked to think of a fictional character that they consider to be a particularly strong example of the trope based on the description provided. The trope descriptions used were verbatim from Eden et al. (2017; adapted from). However, one change was made to the character types: the name of the character type "Disney anti-hero" was changed to "cynical anti-hero" in order to be more conceptually precise and avoid a potential priming effect of the word "Disney". Specifically, there was concern that the inclusion of the word "Disney" may motivate

\footnotetext{
${ }^{1}$ Due to an unexpectedly strong response to the survey advertisement, the final sample for the study was above the estimate based on the power analysis.
} 
participants to select only characters associated with Disney. The defining characteristics of the type (according to TV Tropes) include cynicism and character development. The most commonly character selected for each trope are as follows: hero: Spiderman $(n=7$; $18 \%$ of category); cynical anti-hero: Deadpool $(n=6 ; 19 \%)$; pragmatic anti-hero: Dexter (Dexter, TV series; $n=7 ; 19 \%$ ); classical anti-hero: Elsa (Frozen; $n=3 ; 9 \%$ ); unscrupulous hero: Batman $(n=3 ; 10 \%)$; nominal hero: Dexter (Dexter, TV series; $n=5$; 13\%); villain: The Joker (Batman villain; $n=10 ; 27 \%$ ). See Appendix A for trope descriptions used in the study.

Just as in the original study, participants provided the character example, along with the character's sex, age, and origin, which were taken to indicate the participants' general familiarity with the characters. Participants were then asked to briefly (in 3 to 6 sentences) describe the qualities and characteristics that make the character fit the provided description. In reference to the chosen character, participants completed measures of perceived character morality, self-expansion, wishful identification, homophily, inclusion of other in self, and enjoyment and appreciation (all described below; see Table 2 for correlations between all study variables).

\section{Measures}

Character morality measure. The extended character morality questionnaire (Grizzard et al., 2019) was used to assess perceived character morality. Noting the importance of character morality to several theoretical perspectives, including ADT (see Zillmann, 2000), social cognitive theory (Bandura, 2001), and parasocial interaction (Horton \& Wohl, 1956), Grizzard et al. (2019) sought to improve the original CMFQ (Eden et al., 2015), which was used by Eden et al. (2017). Grizzard et al. (2019) 
expanded the original CMFQ in order to more robustly assess the statistical validity of the factor structure, and demonstrated the validity of the CMFQ-X over the course of six studies. The CMFQ- $\mathrm{X}$ is a 20 -item measure which assesses five moral domains (based on moral foundations theory; see Haidt \& Joseph, 2007): care (4 items, $\alpha=.86, M=3.40$, $S D=1.80$ ), fairness ( 4 items, $\alpha=.85, M=3.98, S D=1.61$ ), loyalty ( 4 items, $\alpha=.89, M$ $=4.83, S D=1.71$ ), authority (4 items, $\alpha=.86, M=3.06, S D=1.60$ ), purity (4 items, $\alpha=$ $.80, M=4.00, S D=1.58)$. The CMFQ-X measures perceived morality according to upholding, not violating, dimensions of morality, therefore, patterns of morality will be assessed as such.

Self-Expansion. The 14-item Self-Expansion Questionnaire (SEQ; Mattingly \& Lewandowski, 2013; Shedlosky-Shoemaker et al., 2014) was used to assess perceived self-expansion. Participants rated their perception of the truthfulness of statements ranging from 1 (not at all true) to 7 (very true; $\alpha=.94 ; M=2.79, S D=1.32$ ).

Wishful Identification. While the original study assessed wishful identification via a single-item measure asking participants to state if they would like to be like the character, the present study used a 3 -item measure of wishful identification $(\alpha=.89, M=$ 2.93, $S D=1.72$ ) used in previous media effects research (Eyal \& Rubin, 2003; Hoffner, 1996; Hoffner \& Buchanan, 2005), following the same 1 (strongly disagree) to 7 (strongly agree) scale range.

Value Homophily. While the original study assessed perceived homophily with the character via a single-item, the present study used a 10-item measure of value homophily $(\alpha=.93, M=3.24, S D=1.57$ ) adapted from past research (Andersen $\&$ Todd de Mancillas, 1978; Downs, Bowman, \& Banks, 2017; Eyal \& Rubin, 2003), following 
the same 1 (strongly disagree) to 7 (strongly agree) response format.

For both wishful identification and value homophily, multi-item measures were used in place of single-item measures because while single item measures can be appropriate for certain constructs, the nuance associated with perceptions related to the self (see Cohen, 2001, 2009) suggested that measurement of these variables may particularly benefit from the use of more robust measures. Additionally, it is a wellknown issue that it is challenging to establish the validity and reliability of single item measures (c.f., Diamantopoulos, Sarstedt, Fuchs, Wilczynski, \& Kaiser, 2012).

Inclusion of Other in Self (IOS) Scale. Inclusion of other in self was measured by Aron, Aron, and Smollan's (1992) IOS scale, a single-item measure that presents participants with seven different pictures of two circles with varying degrees of overlap (as in a Venn Diagram). Participants chose the image which best reflected their relationship/overlap with the character $(M=2.27, S D=1.34)$. Higher numbered responses (ranging from 1 to 7 ) are taken to suggest greater perceived self-other overlap.

Enjoyment and Appreciation. Enjoyment and appreciation were measured by using items adapted from Oliver and Bartsch (2010), as were used in the original study. Participants rated their responses on seven-point Likert-type scales, ranging from 1 (strongly disagree) to 7 (strongly agree). Enjoyment was measured by items adapted from the "fun" dimension ( 3 items; $\alpha=.80, M=5.04, S D=1.43$ ), while appreciation was measured by combining items from the "moving/thought-provoking" and "lasting impression" dimensions (6 items; $\alpha=.88, M=4.22, S D=1.43$ ). 
Table 2. Correlations between all study variables.

\begin{tabular}{|c|c|c|c|c|c|c|c|c|c|c|c|c|}
\hline & 1 & 2 & 3 & 4 & 5 & 6 & 7 & 8 & 9 & 10 & 11 & 12 \\
\hline \multicolumn{13}{|l|}{ 1. Care (Harm) } \\
\hline 2. Fairness & $.757 * *$ & & & & & & & & & & & \\
\hline 3. Loyalty & $.515^{* *}$ & $.694 * *$ & & & & & & & & & & \\
\hline 4. Authority & $.738^{* *}$ & $.668 * *$ & $.480 * *$ & & & & & & & & & \\
\hline 5. Purity & $.691 * *$ & $.716 * *$ & $.590 * *$ & $.708 * *$ & & & & & & & & \\
\hline $\begin{array}{l}\text { 6. Morality } \\
\text { Composite }\end{array}$ & $.874 * *$ & $.901 * *$ & $.773 * *$ & $.842 * *$ & $.866^{* *}$ & & & & & & & \\
\hline 7. Self-Expansion & $.173 * *$ & $.213 * *$ & $.188 * *$ & $.169 * *$ & $.204 * *$ & $.222 * *$ & & & & & & \\
\hline 8. Wishful ID & $.490 * *$ & $.551 * *$ & $.459 * *$ & $.427 * *$ & $.536 * *$ & $.579 * *$ & $.494 * *$ & & & & & \\
\hline 9. Homophily & $.516^{* *}$ & $.582 * *$ & $.498 * *$ & $.449 * *$ & $.552 * *$ & $.610 * *$ & $.469 * *$ & $.837 * *$ & & & & \\
\hline 10. IOS & $.288 * *$ & $.277 * *$ & $.204 * *$ & $.218 * *$ & $.249 * *$ & $.291 * *$ & $.522 * *$ & $.554 * *$ & $.673 * *$ & & & \\
\hline 11. Self Composite & $.456^{* *}$ & $.505 * *$ & $.421 * *$ & $.393 * *$ & $.481 * *$ & $.530 * *$ & $.725^{* *}$ & $.890 * *$ & $.901 * *$ & $.801 * *$ & & \\
\hline 12. Enjoyment & $.150^{*}$ & $.257 * *$ & $.345^{* *}$ & 0.027 & $.207 * *$ & $.233 * *$ & $.256^{* *}$ & $.307 * *$ & $.361 * *$ & $.215^{* *}$ & $.346^{* *}$ & \\
\hline 13. Appreciation & $.127 *$ & $.233 * *$ & $.302 * *$ & 0.078 & $.169 * *$ & $.214 * *$ & $.511 * *$ & $.509 * *$ & $.527 * *$ & $.404 * *$ & $.587 * *$ & $.530 * *$ \\
\hline
\end{tabular}




\section{Results}

\section{Research Question 1}

Research question one asks whether MACs, as defined by character tropes found in popular media culture, exhibit variable morality based on specific moral dimensions. In other words, the question is whether character types will vary according to variation in particular moral domains, or if they would vary across all moral domains, as found by Eden et al. (2017). In order to assess this research question, a multivariate analysis of variance (MANOVA) was conducted with trope condition as the independent variable and the five moral domains as dependent variables. The data was found to significantly violate the assumption of equality of covariance, Box's $M=141.55, F(90,75528.45)=$ $1.48, p=.002$. There were statistically significant differences in perceived moral upholding across character type, $F(30,1185)=5.81, p<.001$, Pillai's Trace $=.641$, partial $\eta^{2}=.128$. Analysis of between-subjects effects indicated significant differences across all five moral domains: care $F(6,237)=18.80, p<.001$, partial $\eta^{2}=.322$; fairness $F(6,237)=21.91, p<.001$, partial $\eta^{2}=.357 ;$ loyalty $F(6,237)=21.48, p<.001$, partial $\eta^{2}$ $=.352$; authority $F(6,237)=11.32, p<.001$, partial $\eta^{2}=.238$, see Figure 1 for a plot of means, and Table 3 for means, standard deviations, and post-hoc mean comparisons between trope conditions.

Notably, the measure of perceived character morality used by Eden et al. (i.e., the CMFQ; Eden et al., 2015) assessed perceived moral violation, whereas the measure used in the present study (i.e., the CMFQ-X; Grizzard et al., 2019) assessed moral upholding. Although it should not be simply assumed that moral violation and moral upholding can be meaningfully compared, the fact that the scale items generally followed a similar 
question format (including several shared items), and that the majority (85\%) of items on the CMFQ-X are reverse coded, suggested that the two scales do represent the same construct.

Figure 1. Moral upholding composites, by character condition.

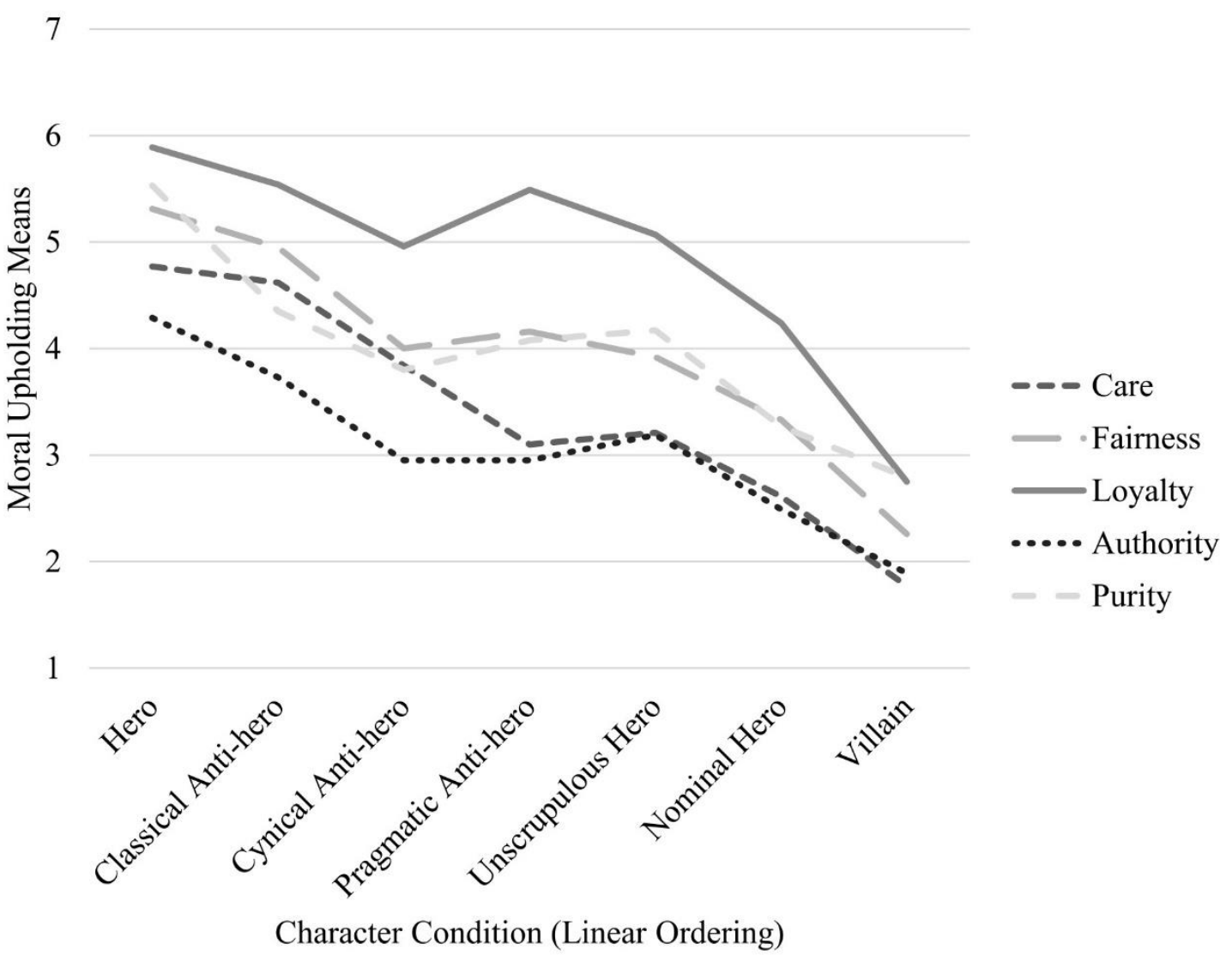

These results are consistent with Eden et al.'s (2017) original findings, in that differences in perceived morality across all five moral domains were found between the trope conditions. Eden et al. noted that reordering the classical anti-hero type to beside the hero type caused the character types to form a linear trend according to perceived morality, such that the ordered character types could be interpreted as a continuum ranging from most morally good to most morally bad (see Figure 1). While both studies support a continuum, it should be noted that Figure 1 shows a negative trend of perceived 
moral upholding across character types, whereas Eden et al. (2017) showed a positive trend of perceived moral violation across character types (as a result of the measure of perceived character morality used in each study). Given that the results of this study replicated the original findings of Eden et al. for research question 1, suggesting that trope conditions (i.e., character types) could be considered as a continuum ranging in terms of perceived morality, the decision to reorder the trope conditions was likewise replicated for subsequent analyses.

Table 3. Means of moral upholding scores for each moral foundation, by condition.

\begin{tabular}{|c|c|c|c|c|c|}
\hline & Care & Fairness & Loyalty & Authority & Purity \\
\hline $\begin{array}{l}\text { Hero } \\
n=39\end{array}$ & $\begin{array}{l}4.77 \mathrm{a} \\
(1.56)\end{array}$ & $\begin{array}{l}5.31 \mathrm{a} \\
(1.29)\end{array}$ & $\begin{array}{l}5.89 \mathrm{a} \\
(1.18)\end{array}$ & $\begin{array}{l}4.29 \mathrm{a} \\
(1.42)\end{array}$ & $\begin{array}{l}5.53 a \\
(1.39)\end{array}$ \\
\hline $\begin{array}{l}\text { Classical } \\
\text { Anti-hero } \\
n=32\end{array}$ & $\begin{array}{l}4.62 \mathrm{a} \\
(1.70)\end{array}$ & $\begin{array}{l}4.95 \mathrm{a}, \mathrm{b} \\
(1.48)\end{array}$ & $\begin{array}{l}5.54 \mathrm{a} \\
(1.31)\end{array}$ & $\begin{array}{l}3.73 a, b \\
(1.86)\end{array}$ & $\begin{array}{l}4.35 \mathrm{~b} \\
(1.69)\end{array}$ \\
\hline $\begin{array}{l}\text { Cynical } \\
\text { Anti-hero } \\
n=32\end{array}$ & $\begin{array}{l}3.84 \mathrm{a}, \mathrm{b} \\
(1.46)\end{array}$ & $\begin{array}{l}4.00 \mathrm{~b}, \mathrm{c} \\
(1.17)\end{array}$ & $\begin{array}{l}4.96 \mathrm{~b} \\
(1.32)\end{array}$ & $\begin{array}{l}2.95 \mathrm{~b}, \mathrm{c}, \mathrm{d} \\
(1.27)\end{array}$ & $\begin{array}{l}3.80 \mathrm{~b}, \mathrm{c} \\
(1.29)\end{array}$ \\
\hline $\begin{array}{l}\text { Pragmatic Anti- } \\
\text { hero } \\
n=37\end{array}$ & $\begin{array}{l}3.10 \mathrm{~b} \\
(1.56)\end{array}$ & $\begin{array}{l}4.16 \mathrm{~b}, \mathrm{c} \\
(1.49)\end{array}$ & $\begin{array}{l}5.49 \mathrm{a} \\
(1.42)\end{array}$ & $\begin{array}{l}2.95 \mathrm{~b}, \mathrm{c}, \mathrm{d} \\
(1.44)\end{array}$ & $\begin{array}{l}4.08 \mathrm{~b} \\
(1.34)\end{array}$ \\
\hline $\begin{array}{l}\text { Unscrupulous } \\
\text { Hero } \\
n=29\end{array}$ & $\begin{array}{l}3.21 \mathrm{~b} \\
(1.62)\end{array}$ & $\begin{array}{l}3.92 \mathrm{~b}, \mathrm{c} \\
(1.38)\end{array}$ & $\begin{array}{l}5.07 \mathrm{a}, \mathrm{b} \\
(1.40)\end{array}$ & $\begin{array}{l}3.19 b, c \\
(1.46)\end{array}$ & $\begin{array}{l}4.17 \mathrm{~b} \\
(1.37)\end{array}$ \\
\hline $\begin{array}{l}\text { Nominal Hero } \\
n=38\end{array}$ & $\begin{array}{l}2.61 b, c \\
(1.33)\end{array}$ & $\begin{array}{l}3.33 \mathrm{c}, \mathrm{d} \\
(1.24)\end{array}$ & $\begin{array}{l}4.24 \mathrm{~b} \\
(1.55)\end{array}$ & $\begin{array}{l}2.49 \mathrm{c}, \mathrm{d} \\
(1.23)\end{array}$ & $\begin{array}{l}3.27 \mathrm{~b}, \mathrm{c} \\
(1.24)\end{array}$ \\
\hline $\begin{array}{l}\text { Villain } \\
n=37\end{array}$ & $\begin{array}{l}1.77 \mathrm{c} \\
(1.28)\end{array}$ & $\begin{array}{l}2.26 \mathrm{~d} \\
(1.10)\end{array}$ & $\begin{array}{l}2.75 c \\
(1.54)\end{array}$ & $\begin{array}{l}1.89 \mathrm{c}, \mathrm{d} \\
(1.28)\end{array}$ & $\begin{array}{l}2.79 \mathrm{c} \\
(1.14)\end{array}$ \\
\hline
\end{tabular}

NOTES: Composite means and standard deviations (in parentheses) reported above. Means with different subscripts within columns represent statistically significant differences at the $p=.05$ level or greater, using post-hoc Scheffe test.

\section{Hypothesis 1}

Hypothesis 1 predicted that MACs would be associated with greater selfexpansion, wishful identification, value homophily, and IOS than pure heroes or villains. 
In order to test hypothesis 1, a MANOVA was conducted with (reordered) trope condition as the independent variable and the four self-related variables as dependent variables. The data was found to significantly violate the assumption of equal covariance, Box's $M=121.92, F(60,81970.15)=1.93, p<.001$. There were significant differences in self-related variables across character type: $F(24,948)=5.11, p<.001$, Pillai's Trace $=$ .458 , partial $\eta^{2}=.115$. Interpretation of the post-hoc Scheffe tests indicates that these significant differences were not due to stronger effects for MACs, rather, the trend of mean scores in terms of self-related variables generally followed the (re)ordering of the character types. That is, heroes received the highest scores, while other character types were decreasingly lower according the order of the tropes (see Figure 2). Moreover, the significant results of the MANOVA appear to be largely a result of the mean scores for pure heroes and villains (see Table 4 for means, standard deviations, and post-hoc mean comparisons between trope conditions). Therefore, in the present study, Hypothesis 1 is unsupported, replicating the findings of Eden et al. (2017) 
Figure 2. Self-related variable composites, by character condition.

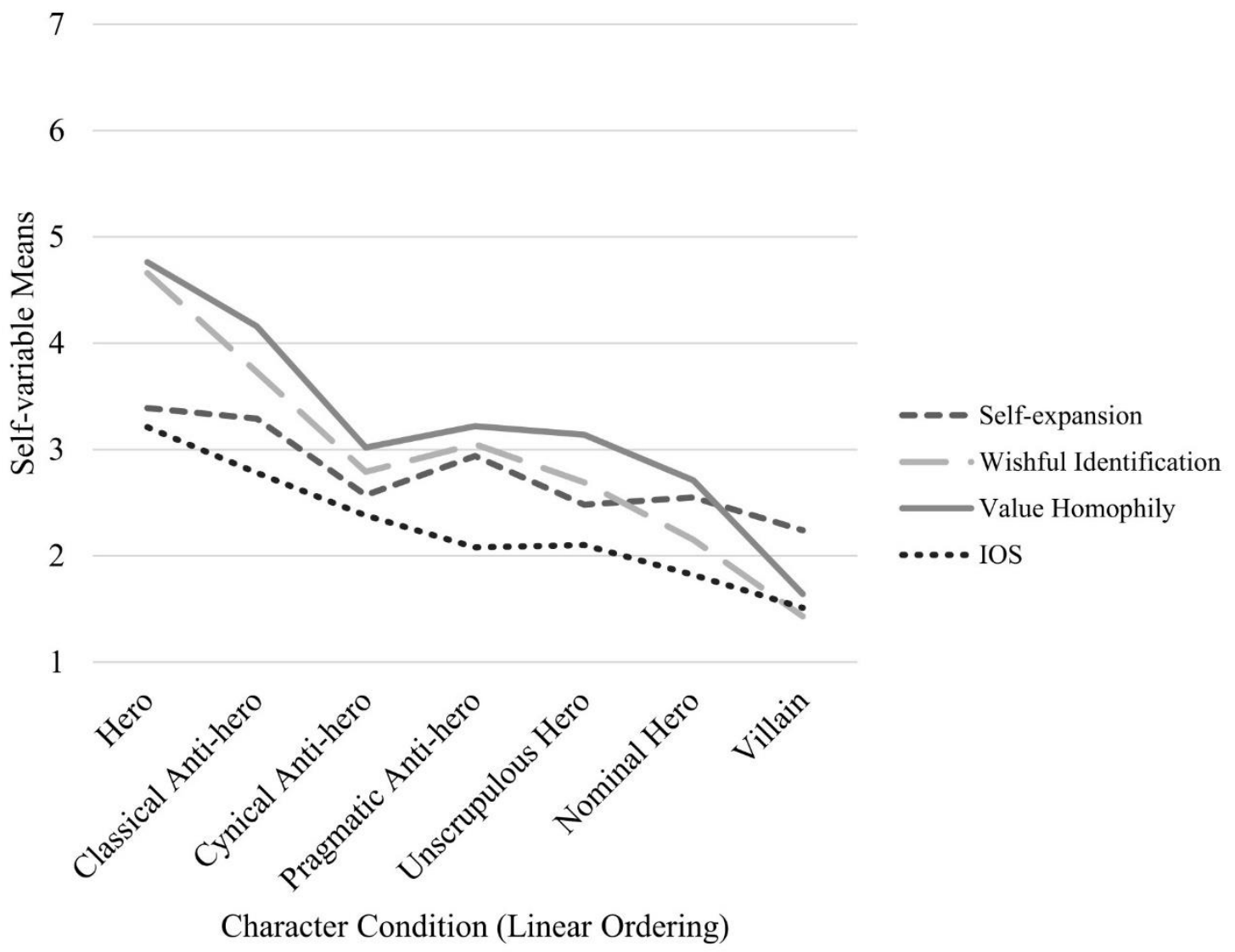

Table 4. Means of self-related variable responses, by condition.

\begin{tabular}{lcccc}
\hline & Self-Expansion & $\begin{array}{c}\text { Wishful } \\
\text { Identification }\end{array}$ & $\begin{array}{c}\text { Value } \\
\text { Homophily }\end{array}$ & $\begin{array}{c}\text { Inclusion of } \\
\text { Other in Self }\end{array}$ \\
\hline Hero & $3.39 \mathrm{a}$ & $4.66 \mathrm{a}$ & $4.76 \mathrm{a}$ & $3.21 \mathrm{a}$ \\
$n=39$ & $(1.42)$ & $(1.36)$ & $(1.21)$ & $(1.49)$ \\
Classical & $3.29 \mathrm{a}, \mathrm{b}$ & $3.73 \mathrm{a}, \mathrm{b}$ & $4.16 \mathrm{a}, \mathrm{b}$ & $2.78 \mathrm{a}, \mathrm{b}$ \\
Antihero & $(1.24)$ & $(1.68)$ & $(1.41)$ & $(1.31)$ \\
$n=32$ & $2.57 \mathrm{a}, \mathrm{b}$ & $2.79 \mathrm{~b}, \mathrm{c}$ & $3.02 \mathrm{c}$ & $2.38 \mathrm{a}, \mathrm{b}$ \\
Cynical & $(1.14)$ & $(1.44)$ & $(1.31)$ & $(1.56)$ \\
$\begin{array}{l}\text { Antihero } \\
n=32\end{array}$ & $2.94 \mathrm{a}, \mathrm{b}$ & $3.05 \mathrm{~b}, \mathrm{c}$ & $3.22 \mathrm{~b}, \mathrm{c}$ & $2.08 \mathrm{~b}, \mathrm{c}$ \\
$\begin{array}{l}\text { Pragmatic } \\
\text { Antihero }\end{array}$ & $(1.19)$ & $(1.62)$ & $(1.34)$ & $(1.12)$ \\
$n=37$ & & & $3.14 \mathrm{~b}, \mathrm{c}$ & $2.10 \mathrm{~b}, \mathrm{c}$ \\
Unscrupulous & $2.48 \mathrm{a}, \mathrm{b}$ & $2.69 \mathrm{~b}, \mathrm{c}$ & $(1.38)$ & $(1.42)$ \\
Hero & $(1.46)$ & $(1.51)$ & &
\end{tabular}


$n=29$

Nominal Hero

2.55a.b

$2.15 \mathrm{c}, \mathrm{d}$

2.71c,d

$1.82 \mathrm{~b}, \mathrm{c}$

$n=38$

Villain

$2.24 b$

$1.43 \mathrm{~d}$

$1.64 d$

$1.51 \mathrm{c}$

$n=37$

(1.17)

(.923)

(.903)

(.731)

NOTES: Composite means and standard deviations (in parentheses) reported above. Means with different subscripts within columns represent statistically significant differences at the $p=.05$ level or greater, using post-hoc Scheffe test.

\section{Hypothesis 2}

Hypothesis 2 predicted that MACs would be more strongly associated with appreciation, and heroes and villains more strongly associated with enjoyment. In order to test hypothesis 2 , separate hierarchical regressions were conducted with enjoyment and appreciation as dependent variables. In both regression models, (reordered) trope condition was entered in the first step, self-expansion, wishful identification, value homophily, and IOS were entered into the second step, and perceived character morality (moral upholding) was entered into the third step. To include morality in the regression model, Eden et al. (2017) collapsed the measures of the five moral domains into a single overall indicator of perceived character morality. This decision was not explained in detail by the original researchers, but there is precedent for collapsing measures in order to reduce model complexity, such as reducing the number of predictors in a statistical model (Park, Dailey, and Lemus, 2002). Additionally, it has been recommended that moral domain scores should be considered in terms of relative domain salience as opposed to absolute score (see Joeckel, Bowman, \& Dogruel, 2013). However, based on the fact that the moral domains scores in the present study appear correlated (see Table 1), it was interpreted that analyzing for the relative salience of individual moral domains in perceived character morality was unnecessary. Furthermore, an unrotated principal 
components analysis reported a single component that explained $72.68 \%$ of variance in the underlying construct, with the following component loadings: care (.874), fairness (.903), loyalty (.759), authority (.847), purity (.872). This was interpreted to validate the appropriateness of a single measure of perceived character morality (moral upholding).

For enjoyment, the regression model was significant at the second step, $F(4,238)$ $=6.50, p<.001$, adj. $r^{2}=.126$, indicating that perceived character morality did not explain significantly more variance at Step $3, \Delta F(1,237)=.038, p=.845, \Delta r^{2} \sim .000$. These results are unlike the results of Eden et al. (2017), who found that morality was significantly associated with enjoyment. In the regression for enjoyment, only value homophily emerged as a significant predictor of enjoyment, Step $2 \beta=.356, p<.001$ (see Table 5 for results of both regressions).

For appreciation, the regression model was significant at the second step, $F(4$, $238)=30.33, p<.001$ adj. $r^{2}=.365$. In the regression for appreciation, only selfexpansion, Step $2 \beta=.322, p<.001$, and value homophily, Step $2 \beta=.317, p=.002$, emerged as significant predictors (see Table 5). Notably, the inclusion of step 3 yielded: $\Delta F(1,237)=3.83, p=.051, \Delta r^{2}=.010$. This result will be discussed further in the discussion section. Additionally, as found by Eden et al. (2017), character type was not significantly related to either enjoyment or appreciation.

Table 5. Regression results for enjoyment and appreciation.

\begin{tabular}{lcccccc}
\hline & \multicolumn{3}{c}{ Enjoyment } & \multicolumn{3}{c}{ Appreciation } \\
\hline & Step 1 & Step 2 & Step 3 & Step 1 & Step 2 & Step 3 \\
\hline Character Type & $-.225^{*}$ & -.031 & -.025 & $-.248^{*}$ & .105 & .053 \\
Self-Expansion & & .137 & .138 & & $.322^{* * *}$ & $.314 * * *$ \\
Wishful & & -.032 & -.035 & & .147 & .169 \\
Identification & & & & & $.317 * *$ & $.373 * * *$ \\
Value & & $.356^{* *}$ & $.349 * *$ & & &
\end{tabular}


Homophily

Inclusion of

$-.077$

$-.074$

$-.005$

$-.029$

Other in Self

Morality

.017

Aggregate

NOTES: $*=p<.05, * *=p<.01, * * *=p<.001$

\section{Additional Analyses}

After replicating the analyses conducted in the original study, two additional steps were taken. First, the regression results for enjoyment and appreciation (H2) suggested potential multicollinearity among the self-related variables of self-expansion, wishful identification, value homophily, and IOS. Therefore, the factor structure of the measures for these variables was investigated. Second, the assumption that the seven character tropes could be thought of as a continuum and treated as a single integer-level variable was challenged. This was done by using dummy-coded variables in a regression model, in order to isolate the effects of each character type on the other variables of interest. These additional analyses are detailed below.

An unrotated principal components analysis on the self-related variables reported a single component that explained $69.29 \%$ of variance in the underlying construct, with the following component loadings: self-expansion (.724), wishful identification (.881), value homophily (.900), IOS (.813). Again, in line with Park et al. (2002), the four measures were collapsed into a single indicator of perceived self-other convergence for a follow-up analysis.

As before, separate hierarchical regressions were conducted with enjoyment and appreciation as dependent variables. In each regression, (reordered) trope condition was entered in the first step, the composite measure of perceived self-other convergence was entered into the second step, and perceived character morality (moral upholding) was 
entered into the third step. Results were similar to the initial regression models: trope condition (Step 1) and perceived character morality (Step 3) were non-significant in both regression models, while perceived self-other convergence (Step 2) was significant in both models. For enjoyment, the Step 2 model was significant, $F(1,241)=19.42, p<$ .001 , adj. $r^{2}=.114$, with Step $2 \beta=.321, p=.001$. For appreciation, the Step 2 model was significant, $F(1,241)=108.98, p<.001$, adj. $r^{2}=.348$, with Step $2 \beta=.652, p<.001$ (See table 6 for results of both regressions). These findings are consistent with those of the original study (i.e., Eden et al., 2017), in that the composite measure of perceived self-other convergence was a stronger predictor of appreciation than enjoyment, explaining over twice as much variance. This finding supports Eden et al.'s (2017) notion that the experience of appreciation is linked to self-related perceptions of characters (e.g., the TEBOTS model).

Table 6. Regression results for enjoyment and appreciation with collapsed self variable.

\begin{tabular}{|c|c|c|c|c|c|c|}
\hline & \multicolumn{3}{|c|}{ Enjoyment } & \multicolumn{3}{|c|}{ Appreciation } \\
\hline & Step 1 & Step 2 & Step 3 & Step 1 & Step 2 & Step 3 \\
\hline Character Type & $-.225 * * *$ & -.045 & -.018 & $-.248 * * *$ & .116 & .069 \\
\hline Self Aggregate & & $.321 * * *$ & $.304 * * *$ & & $.652 * * *$ & $.681 * * *$ \\
\hline Morality & & & .061 & & & -.103 \\
\hline Aggregate & & & & & & \\
\hline
\end{tabular}

In a second follow-up analysis, the notion that the character tropes formed a continuum of perceived morality ranging from hero to villain was examined. First, variables were created for each character type (except hero, as a comparison) by dummy coding either " 1 " (category member) or "0" (non-member). Following the same analysis procedure as the previous regression models, separate hierarchical regression were conducted for enjoyment and appreciation. Therefore, the dummy coded character type 
variables were entered in Step 1, the composite measure of perceived self-other convergence entered in Step 2, and perceived character morality in Step 3. Such an analysis allows for direct comparison of effects across groups (in this case, trope conditions). The resultant regression model for enjoyment was significant at Step 2, $F(1,236)=18.68, p<.001$ adj. $r^{2}=.146$, again with only perceived self-other convergence emerging as a significant predictor, Step $2 \beta=.315, p<.001$. Similarly, the regression for appreciation was significant at Step $2, F(1,236)=101.66, p<.001$, adj. $r^{2}$ $=.355$, also with perceived self-other convergence as the only significant predictor, Step $2 \beta=.638, p<.001$ (see Table 7 for results of both regressions). From these results it was interpreted that none of the dummy coded trope condition variables influenced enjoyment or appreciation at Step 2 in either model, and likewise Step 3 (perceived character morality) was not significant in either model. Therefore, the data supported the notion that character types could be considered as forming a continuum according to perceived morality ranging from most to least moral across all moral domains for the analyses contained within this study. However, it should be noted that because character types were often not significantly different in terms of moral upholding (see Table 3) or Selfrelated variables (see Table 4), the seven tropes should not be assumed to possess the properties of interval-level data.

Table 7. Regression results with dummy coded tropes.

\begin{tabular}{lcccccc}
\hline & \multicolumn{3}{c}{ Enjoyment } & \multicolumn{3}{c}{ Appreciation } \\
\hline & Step 1 & Step 2 & Step 3 & Step 1 & Step 2 & Step 3 \\
\hline Classical Dummy & -.011 & .033 & .035 & .019 & .108 & .098 \\
Cynical Dummy & -.038 & .074 & .079 & $-.259^{* *}$ & -.031 & -.054 \\
Pragmatic Dummy & -.017 & .090 & .096 & -.083 & .135 & .110 \\
Unscrupulous Dummy & -.039 & .076 & .081 & $-.176^{*}$ & .057 & .036 \\
Nominal Dummy & -.039 & .117 & .127 & $-.214^{* *}$ & .103 & .061
\end{tabular}




\begin{tabular}{|c|c|c|c|c|c|c|}
\hline Villain Dummy & $-.346 * * *$ & -.136 & -.122 & $-.276^{* *}$ & .148 & .086 \\
\hline Self Aggregate & & $.315^{* * *}$ & $.308 * * *$ & & $.638 * * *$ & $.667 * * *$ \\
\hline Morality Aggregate & & & .026 & & & -.110 \\
\hline
\end{tabular}

\section{Discussion}

This study sought to investigate the enjoyment and appreciation of morally ambiguous characters by replicating the study of Eden et al. (2017). Based on affective disposition theory, the present study investigated whether media viewers perceive and interpret characters of varying morality according to schemas (Raney, 2004), using character types found in popular media culture (in this study, represented by character types defined via www.tvtropes.com). These character types were then compared by association with variables including self-expansion, wishful identification, homophily and IOS. Finally, like the original study, the present study investigated the effect of character types and related perceptions on enjoyment and appreciation. Broadly, while this study did not reveal why viewers are entertained by media featuring MACs, it contributes to entertainment effects research by confirming and reinforcing the understanding of MACs.

For the research question, the present study replicated the original study's finding that character types varied across all moral domains, and that reordering the classical anti-hero character type to beside the hero type created a linear trend in overall perceived morality ranging from most morally good to most morally bad. Based on Raney's (2004) explanation that viewers use schemas to interpret media, viewers are assumed to use associations drawn from past media experiences to organize knowledge of characters. Perceived morality may constitute such a framework, and in this case according to the TV tropes typology. Review of the post-hoc Scheffe tests from the results of RQ1 
suggests that overall, individual character types were not all that different in terms of perceived morality. Specifically, while heroes and villains are somewhat good anchors in terms of most morally upholding and violating, types of MACs did not greatly differ among each other in perceived morality according to moral domains. However, in many cases (i.e., 4 of 5 moral domains; see Table 3) neither heroes nor villains were significantly different from another character type. This again suggests that caution should be applied when interpreting this character typology as a continuum.

It may be the case that viewers' interpretive processes (i.e., schemas) account for potential variation within individual MACs as being within a singular organizing character type, such that there are really only three categories, heroes, villains and MACs. Therefore, the present findings - in combination with past research that has supported the notion of character morality as falling upon a continuum (e.g., Sanders \& Tsay-Vogel, 2016; Tamborini et al., 2018) — may point toward MACs existing as a single superordinate category. That is, viewers might make unique associations with different specific MACs, but conceptually (and when it comes to schemas), there are not actually types of MACs based on perceived morality (i.e., MFT) that are more explanatory than MACs as a category.

Considering that perceived morality does not appear to adequately explain why viewers might have unique affective dispositions toward specific examples of MACs, the results of the present study may be interpreted to suggest that other aspects of MACs be explored as schema-associated factors. For example, Grizzard et al. (2017) demonstrated that physical attributes of the characters themselves contributed to moral judgments, and that the presence of opposing characters in narratives plays a role in schema activation. 
Additionally, character development over the course of a narrative has been identified as a distinguishing characteristic of anti-heroes (e.g., Janicke \& Raney, 2015; also reflected in some of the character type descriptions used in this study). In addition, the role of perceived morality in ADT suggests that viewers assess the rightness or wrongness of character's actions (Raney, 2006), but not necessarily in terms of moral domains as found in MFT. Therefore, perhaps a more nuanced understanding of viewers' perceptions of MACs might consider different conceptualizations of morality and other schema influences such as character development, in order to provide a clearer understanding of viewers' interpretation of media characters.

Results for hypothesis one demonstrated, in agreement with the original findings of Eden et al. (2017), that MACs are not more strongly related to perceptions of selfexpansion, wishful identification, homophily, or IOS than pure heroes or villains. When considering that self-based perceptions and appreciation responses to media are conceptually linked (Oliver \& Bartsch, 2010), the result that MACs were not more closely related to self-related variables in both studies suggests that it is unlikely that appreciation, as it is currently understood, can alone adequately explain positive audience responses to MACs. Furthermore, while Eden et al. (2017) proposed that character types who vary among particular moral domains (such as found by Eden et al., 2015) may promote self-expansion in viewers based on the domains that they uphold and violate, the fact that characters in both studies did not vary among individual moral domains helps to explain why the TEBOTS model may not be an effective explanation of MACs as they compared to heroes and villains. That is, whereas watching a character's actions as they uphold and violate moral domains may lead to vicarious experiences that expand one's 
sense of self, the findings of this study suggest that viewers' perceptions of moral behavior may not be nuanced enough to allow for such expansion. Simply put, the results of this study suggest that MACs are not more complicated than heroes or villains, rather, they are just not as good as heroes or as bad as villains. Raney (2004) proposed that viewers interpret characters in media through schemas, which may come before the introduction of the character, and influence and/or limit the interpretation of the character. Essentially, viewers already know how they feel about a character either before or very soon after the character is introduced, without the need for moral consideration. Therefore, self-expansion would not be caused by the character itself (for which viewers have a pre-existing schema pattern), but perhaps from the narrative context, as suggested by the TEBOTS model (Slater et al., 2014). Additionally, because viewers already know how they feel about characters (based on schemas), they may morally disengage automatically, without having to establish an affective disposition toward a character (Raney, 2004). In doing so they may deliberately (but not necessarily consciously) misattribute or rationalize a liked characters immoral behavior, which may also detract from the self-expansion experience.

This also highlights the integral role of narrative in the TEBOTS model (Slater et al., 2014). TEBOTS proposes that narrative engagement causes the experience of selfexpansion. Without narrative context, the affective dispositions accessed by participants in the study were presumed to be based around schema structures as proposed by Raney (2004). Based on internalized schemas alone, participants in the present study may have been less likely to align themselves with their chosen character in terms of perceived selfother convergence. Perhaps in the absence of narrative context, which can serve to 
rationalize characters' actions and portray character development over time, participants were unable to sufficiently morally disengage (i.e., justify immoral behavior) from the negative character traits/characteristics conveyed by the descriptions. According to Raney (as cited by Tamborini et al., 2018), the notion of moral disengagement does not suggest that viewers cease to judge a character's actions, but rather that viewers are more likely to justify a character's actions, in alignment with Zillmann's (2000) claim that viewers continuously assess the morality of characters' actions. Moreover, Sanders and TsayVogel (2016) demonstrated that identification (another variable associated with the self; see Cohen, 2001) can be an important mediator of the relationship between the amount of narrative exposure (i.e., time spent with the media) and moral disengagement (both directly and indirectly through moral judgment), depending on character morality. Specifically, results of Sanders and Tsay-Vogel (2016) suggested that characters perceived by viewers to possess greater moral complexity may engender more perspective taking and empathy, as well as be more likely to facilitate moral disengagement through identification, due to them being seen as more realistic (Konijn \& Hoorn, 2005) and relatable (Janicke \& Raney, 2015). Therefore, in the case of morally complex characters such as MACs, viewers may require the context provided by actually seeing media featuring the characters in order to orient their perceptions of self (e.g., selfexpansion, identification) toward characters and to morally disengage. Future research should investigate how actually viewing media content can impact self-oriented perceptual processes. Further, if seeing characters in context can indeed play a role in perceptions related to the self, then researchers may also want to consider potential mediating and/or moderating effects of variables such as narrative engagement (see 
Busselle \& Bilandzic, 2009) and transportation (see Green, Brock, \& Kaufman, 2004), as both involve a sense of entering/being involved in the story, which contributes to selfexpansion by helping viewers understand and feel empathetic toward characters (see Slater et al., 2014).

In terms of hypothesis two, there were several interesting results from the present study. It was initially found that self-expansion was the only variable significantly associated with enjoyment, while self-expansion and value homophily were significantly associated with appreciation. This partially aligned with the findings of Eden et al.'s (2017) original study, which found that self-expansion was significantly associated with both enjoyment and appreciation. However as detailed in the results, the self-related variables (i.e., self-expansion, wishful identification, homophily, IOS) were collapsed into a single variable of perceived self-other convergence, as a factor analysis suggested that they represented a single underlying construct. The finding that self-expansion, wishful identification, homophily, and IOS were operationally indistinct may also be taken to suggest that participants did not distinguish between the different forms of selfbased perceptions. The collapsed variable was inserted into the same regression models in lieu of the four self-related variables, and was significantly positively related to both enjoyment and appreciation. This result reflects Eden et al.'s (2017) finding that selfexpansion and wishful identification were significantly positively related to enjoyment and appreciation. Furthermore, across the two studies the standardized beta for selfexpansion (original study: enjoyment Step $2 \beta=.22, p<.01$; appreciation Step $2 \beta=.58$, $p<.001$ ) and the collapsed self-variable (current study: enjoyment Step $2 \beta=.32, p<$ .001 ; appreciation Step $2 \beta=.65, p<.001)$ were of similar magnitude, and in both cases 
each variable explained over twice as much variance in appreciation than enjoyment. Therefore, the results of these study seem to support Eden et al.'s (2017) suggestion that morality is related to enjoyment while (some form of) perceived self-other convergence is related to appreciation.

Additionally, it is notable that this study failed to replicate a relationship between enjoyment and perceived character morality as found by Eden et al. (2017). The lack of any significant relationship between perceived morality and enjoyment and appreciation suggest that character morality (as presumed to be manipulated by the typology employed in this study) is not enough to account for media experience outcomes. This may again suggest that character factors other than morality are associated with schemas. However, it should also be acknowledged that the effect of perceived morality on appreciation in the initial regression analysis (i.e., containing the un-collapsed self-related variables) was near significance at the traditional level $(p=.051)$, and possessed a similar standardized beta (Step $3 \beta=-.14$ ) as the original study found for the effect of morality on enjoyment (Step $3 \beta=-.19$ ). This suggests that perhaps morality may yet play a role in the experience of appreciation, contrary to what Eden et al. (2017) suggested. It may be possible that the perceived morality of media characters is related to both enjoyment and appreciation, while self-related perceptions such as self-expansion are more closely related to appreciation than enjoyment. Future research will need to continue to investigate the role of perceived character morality in the experience of enjoyment and appreciation.

It should be discussed that Eden et al. (2017) suggested that one explanation for their findings related to a previous study of the TEBOTS model (i.e., Johnson, Ewoldsen, 
$\&$ Slater, 2015). That study found that strains to the self-concept (ego-depletion) were positively related to self-expansion. Based on their finding that morality related to enjoyment, while self-expansion was more strongly related to appreciation, Eden et al. (2017) suggested that these variables may facilitate each respective entertainment outcome. Drawing from the findings of Johnson et al. (2015), Eden et al. proposed that perhaps the satisfaction of intrinsic needs (e.g., competence, autonomy, relatedness; see Ryan and Deci, 2001) may be related to appreciation (cf. Vorderer \& Ritterfield, 2009). However, as both the original study and the present study do not assess intrinsic needs, this claim lacks the support necessary to critically assess.

One potential candidate to explain the findings for hypothesis two comes from the theoretical framework. Like the TEBOTS model, narrative exposure is considered to be an integral element of affective disposition theory. Specifically, ADT theorizes that the alignment of characters' narrative outcomes with viewers' expectations (based on affective dispositions) is the cause of perceptions of enjoyment (see Raney, 2004). It may be possible that the influence of perceived morality on entertainment outcomes of enjoyment and appreciation can be better characterized as an indirect or interaction effect of its relationship with narrative. It seems likely to be the case that the entertainment experience necessitates seeing characters in action (i.e., within narrative context) in order for monitoring of their moral behavior to have a meaningful influence on perceptions of enjoyment and/or appreciation. As this study tested schematic perceptions of characters according to type (e.g., Raney, 2004), the lack of narrative stimuli was treated as an acceptable limitation of the study. However, future research should consider how actually viewing characters may play a role in the processes of enjoyment and appreciation. 


\section{Limitations and Future Research Directions}

This study possessed several limitations. First, in following a direct conceptual replication of Eden et al.'s (2017) original study, this study recognizes some of the same limitations as identified by the original work. Specifically, the original authors noted that (1) the study was based on character types as defined by only a popular website, and (2) the characters reported on were self-chosen by participants.

As previously noted, the TV Tropes typology used in both this study and by Eden et al. (2017) represents only one potential organizing framework for character types. Based on the findings of the present study, providing further evidence that MACs vary in overall morality, future research potentially involving subtypes within MACs should consider alternate typologies of MACs, such as that offered by Tamborini et al. (2018). Tamborini et al.'s typology consists of five character types ranging from most moral (i.e., "perfect hero") to least moral (i.e., "perfect villain") in overall perceived morality as opposed to in individual moral domains, more closely reflecting the findings of both this and the original study (i.e., Eden et al., 2017).

That the characters participants reported on in this study (and in the original) were self-chosen by participants may have implications for the results of the present study (Eden et al., 2017). Eden et al. (2017) acknowledged that this method may have limited the diversity of specific characters selected, and that the same characters were selected for multiple tropes (a finding also observed in the present study). The fact that the same characters overlapped onto different tropes may suggest that the character types used were not sufficiently distinct (Eden et al., 2017), or that other characteristics provided by the descriptions besides morality may have influenced participants' selections. Relatedly, 
it is a limitation of the present study (and of the original study) that participants' rationale for character choices (i.e., the open-ended data) was not analyzed. An emergent thematic analysis of the qualitative data provided by participants may suggest unique or shared themes associated with character types, which might give insight into the present findings, such as suggesting schema activation. Future research on MACs should seek to understand the nuanced associations that viewers make based on affective dispositions toward specific characters and schemas that they might hold.

Beyond those limitations of the original study, the present study was also limited in unique ways. One limitation of this study was that the sample was recruited from a single US university, which challenges the generalizability of these findings. While it has been suggested that convenience sampling may be less of a concern for replicated research conducted across varied samples (McEwan, Carpenter, \& Westerman, 2018), these results should still be interpreted with this limitation in mind. Future research should investigate perceptions of MACs across different samples, with a focus on generalizability. Although research on moral foundations theory suggests that morality is dependent on culture (see Haidt \& Joseph, 2007), research across audience characteristics will aid in moving toward a robust understanding of the role of perceived morality in interpretations of media. Another limitation of the present study is that certain measures — namely the measures of perceived character morality, value homophily, and wishful identification - were not the same used in the original study, rendering the current study not a complete replication. The limitation of using the updated CMFQ-X (Grizzard et al., 2019) was accepted due to its demonstrated improvement in terms of reliability and validity over the original CMFQ, and changing from single-item to multi- 
item scales for wishful identification and value homophily due to the known issues concerning single-item measures (see Diamantopoulos et al., 2012). However, despite the anticipated measurement improvements, it is important to consider potential differences when comparing the two studies.

\section{Conclusion}

The partially replicated findings of Eden et al. (2017) reported in this study contribute to entertainment effects research by providing evidence that (1) perceptions of character types may be conceptualized as existing on a continuum of overall morality, (2) that MACs are no more related to self-related perceptions than heroes or villains, and (3) that aggregated self-related perceptions of media (i.e., perceived self-other convergence) are associated with both enjoyment and appreciation, accounting for perceived character morality and character type. Broadly, the results of the present study indicate that while MACs are distinct from heroes and villains, there does not seem to be a great deal of variation (at least in terms of perceived morality) within subtypes of MACs. Additionally, media perceptions related to the self (i.e., the collapsed variable of self-expansion, wishful identification, value homophily, and IOS) appear to be related to both enjoyment and appreciation. This suggests that other character-based associations could be included in the schemas used in affective dispositions, and highlights the important role of narrative context in both self-related media perceptions (e.g., TEBOTS; Slater et al., 2014) and affective disposition theory (Zillmann, 2000). In terms of explaining why and how viewers respond positively to MACs, this study contributes to previous literature by partially replicating Eden et al.'s (2017) findings and contributes to the understanding of MACs in media. 


\section{References}

Andersen, P. A., \& Todd de Mancillas, W. R. (1978). Scales for the measurement of homophily with public figures. Southern Speech Communication Journal, 43, 169-179. doi:10.1080/10417947809372379

Aron, A., Aron, E. N., \& Smollan, D. (1992). Inclusion of other in the self scale and the structure of interpersonal closeness. Journal of Personality and Social Psychology, 63, 596-612. doi:10.1037/0022-3514.63.4.596

Bandura, A. (1986). Social foundations of thought and action: A social cognitive theory. Englewood Cliffs, NJ, US: Prentice-Hall, Inc.

Bandura, A. (2001). Social cognitive theory of mass communication. Media Psychology, 3, 265-299. doi:10.1207/s1532785xmep0303_03

Busselle, R., \& Bilandzic, H. (2009). Measuring narrative engagement. Media Psychology, 12, 321-347. doi:10.1080/15213260903287259

Cohen, J. (2001). Defining identification: A theoretical look at the identification of audiences with media characters. Mass Communication and Society, 4, 245-264. doi: $10.4324 / 9781315164441-14$

Cohen, J. (2009). Mediated relationships and media effects: Parasocial interaction and identification. In R. L. Nabi \& M. B. Oliver (Eds.) The SAGE handbook of media processes and effects. Thousand Oaks, CA: SAGE publications, Inc.

Daalmans, S., Hijmans, E., \& Wester, F. (2013, August). The good, the bad and the ambivalent?: Exploring the moral nature of fiction characters over time. Paper presented at the annual conference of the Association for Education in Journalism and Mass Communication, Washington, DC. 
Daalmans, S., Hijmans, E., \& Wester, F. (2017). From good to bad and everything in between: An analysis of genre differences in the representation of moral nature. Journal of Media Ethics, 32, 28-44. doi:10.1080/23736992.2016.1258992

Diamantopoulos, A., Sarstedt, M., Fuchs, C., Wilczynski, P., \&amp; Kaiser, S. (2012). Guidelines for choosing between multi-item and single-item scales for construct measurement: A predictive validity perspective. Journal of the Academy of Marketing Science, 40, 434-449. doi:10.1007/s11747-011-0300-3

Downs, E., Bowman, N. D., \& Banks, J. (2017). A polythetic model of player-avatar interaction: Synthesizing multiple mechanisms. Psychology of Popular Media Culture. Advance online publication. doi:10.1037/ppm0000170

Eden, A., Grizzard, M., \& Lewis, R. J. (2011). Disposition development in drama: The role of moral, immoral and ambiguously moral characters. International Journal of Arts and Technology, 4, 33-47. doi:10.1504/IJART.2011.037768

Eden, A., Daalmans, S., \& Johnson, B. K. (2017). Morality predicts enjoyment but not appreciation of morally ambiguous characters. Media Psychology, 20, 349-373. doi:10.1080/15213269.2016.1182030

Eden, A., Oliver, M. B., Tamborini, R., Limperos, A., \& Woolley, J. (2015). Perceptions of moral violations and personality traits among heroes and villains. Mass Communication and Society, 18, 186-208. doi:10.1080/15205436.2014.923462

Eden, A., \& Tamborini, R. (2017). Moral intuitions: Morality subcultures in disposition formation. Journal of Media Psychology, 29, 198-207. doi:10.1027/1864$1105 / \mathrm{a} 000173$

Eyal, K, \& Rubin, A. M. (2003). Viewer aggression and homophily, identification, and 
parasocial relationships with television characters. Journal of Broadcasting \& Electronic Media, 57, 77-98. doi:10.1207/s15506878jobem4701_5

Faul, F., Erdfelder, E., Buchner, A., \& Lang, A.-G. (2009). Statistical power analyses using G*Power 3.1: Tests for correlation and regression analyses. Behavior Research Methods, 41, 1149-1160. doi:10.3758/brm.41.4.1149

Faul, F., Erdfelder, E., Lang, A.-G., \& Buchner, A. (2007). G*Power 3: A flexible statistical power analysis program for the social, behavioral, and biomedical sciences. Behavior Research Methods, 39, 175-191. doi:10.3758/bf03193146

Graham, J., Nosek, B. A., Haidt, J., Iyer, R., Koleva, S., \& Ditto, P. H. (2011). Mapping the moral domain. Journal of Personality and Social Psychology, 101, 366-385. doi:10.1037/a0021847

Green, M. C., Brock, T. C., \& Kaufman, G. F. (2004). Understanding media enjoyment: The role of transportation into narrative worlds. Communication Theory, 14, 311327. doi:10.1111/j.1468-2885.2004.tb00317.x

Grizzard, M., Fitzgerald, K., Francemore, C. J., Ahn, C., Huang, J., Walton, J., McAllister, C., \& Eden, A. (2019). Validating the extended character morality questionnaire. Media Psychology. Advance online publication. doi:10.1080/15213269.2019.1572523

Grizzard, M., Huang, J., Fitzgerald, K., Ahn, C., \& Chu, H. (2017). Sensing heroes and villains: Character-schema and the disposition formation process. Communication Research, 45, 479-501. doi:10.1177/0093650217699934

Haidt, J., \& Joseph, C. (2007). The moral mind: How five sets of innate intuitions guide the development of many culture-specific virtues, and perhaps even modules. In 
P. Carruthers, S. Laurence, \& S. Stich (Eds.), Evolution and cognition. The innate mind Vol. 3. Foundations and the future (pp. 367-391).

doi:10.1093/acprof:oso/9780195332834.003.0019

Hoffner, C. (1996). Children's wishful identification and parasocial interaction with favorite television characters. Journal of Broadcasting \& Electronic Media, 40, 389-402. doi:10.1080/08838159609364360

Hoffner, C., \& Buchanan, M. (2005). Young adults' wishful identification with television characters: The role of perceived similarity and character attributes. Media Psychology, 7, 325-351. doi:10.1207/S1532785XMEP0704_2

Hoffner, C., \& Cantor, J. (1991). Factors affecting children's enjoyment of a frightening film sequence. Communication Monographs, 58, 41-62. doi:10.1080/03637759109376213

Horton, D., \& Wohl, R. R. (1956). Mass communication and para-social interaction. Psychiatry, 19, 215-229. doi:10.1080/00332747.1956.11023049

Janicke, S. H., \& Raney, A. A. (2015). Exploring the role of identification and moral disengagement in the enjoyment of an antihero television series. Communications, 40, 485-495. doi:10.1515/commun-2015-0022

Jaschik, S. (2017, February). Professors and politics: What the research says. Retrieved from: https://www.insidehighered.com/news/2017/02/27/research-confirmsprofessors-lean-left-questions-assumptions-about-what-means

Joeckel, S., Bowman, N. D., \& Dogruel, L. (2013). The influence of adolescents' moral salience on actions and entertainment experience in interactive media. Journal of Children and Media, 7, 480-506. doi:10.1080/17482798.2013.781513 
Johnson, B. K., Ewoldsen, D. R., \& Slater, M. D. (2015). Self-control depletion and narrative: Testing a prediction of the TEBOTS model. Media Psychology, 18, 196-220. doi:10.1080/15213269.2014.978872

Johnson-Laird, P. N. (1983). Mental models: Towards a cognitive science of language, inference, and consciousness. Cambridge, MA: Harvard University Press.

Kinnally, W., Tuzunkan, F., Raney, A. A., Fitzgerald, M., \& Smith, J. K. (2013). Using the schema-triggered affect model to examine disposition formation in the context of sports news. Journal of Sports Media, 8, 117-137. doi:10.1353/jsm.2013.0000

Kleemans, M., Eden, A., Daalmans, S., van Ommen, M., \& Weijers, A. (2017). Explaining the role of character development in the evaluation of morally ambiguous characters in entertainment media. Poetics, 60, 16-28. doi:10.1016/j.poetic.2016.10.003

Konijn, E. A., \& Hoorn, J. F. (2005). Some like it bad: Testing a model for perceiving and experiencing fictional characters. Media Psychology, 7, 107-144. doi:10.1207/S1532785XMEP0702_1

Krakowiak, K. M. (2015). Some like it morally ambiguous: The effects of individual differences on the enjoyment of different character types. Western Journal of Communication, 79, 472-491. doi:10.1080/10570314.2015.1066028

Krakowiak, K. M., \& Oliver, M. B. (2012). When good characters do bad things: Examining the effect of moral ambiguity on enjoyment. Journal of Communication, 62, 117-135. doi:10.1111/j.1460-2466.2011.01618.x

Krakowiak, K. M., \& Tsay, M. (2011). The role of moral disengagement in the enjoyment of real and fictional characters. International Journal of Arts and 
Technology, 4, 90-101. doi:10.1504/IJART.2011.037772

Krakowiak, K. M., \& Tsay-Vogel, M. (2013). What makes characters' bad behaviors acceptable?: The effects of character motivation and outcome on perceptions, character liking, and moral disengagement. Mass Communication and Society, 16, 179-199. doi:10.1080/15205436.2012.690926

Krakowiak, K. M., \& Tsay-Vogel, M. (2015). The dual role of morally ambiguous characters: examining the effect of morality salience on narrative responses. Human Communication Research, 41, 390-411. doi:10.1111/hcre.12050

Lewis, R. J., Tamborini, R., \& Weber, R. (2014). Testing a dual-process model of media enjoyment and appreciation. Journal of Communication, 64, 397-416. doi:10.1111/jcom.12101

Mattingly, B. A., \& Lewandowski, G. W. (2013). The power of one: benefits of individual self-expansion. The Journal of Positive Psychology, 8, 12-22. doi:10.1080/17439760.2012.746999

McEwan, B., Carpenter, C. J., \& Westerman, D. (2018). On replication in communication science. Communication Studies, 69, 235-241. doi:10.1080/10510974.2018.1464938

Newport, F. (2016). Five key findings on religion in the U.S. Retrieved from: https://news.gallup.com/poll/200186/five-key-findings-religion.aspx OECD. (2014). Education at a glance 2014. Retrieved from: http://www.oecd.org/education/Netherlands-EAG2014-Country-Note.pdf

Oliver, M. B. (1993). Exploring the paradox of the enjoyment of sad films. Human Communication Research, 19, 315-342. doi:10.1111/j.1468-2958.1993.tb00304.x 
Oliver, M. B. (2008). Tender affective states as predictors of entertainment preference. Journal of Communication, 58, 40-61. doi:10.1111/j.1460-2466.2007.00373.x

Oliver, M. B., \& Bartsch, A. (2010). Appreciation as audience response: Exploring entertainment gratifications beyond hedonism. Human Communication Research, 36, 53-81. doi:10.1111/j.1468-2958.2009.01368.x

Oliver, M. B., \& Raney, A. A. (2011). Entertainment as pleasurable and meaningful: Identifying hedonic and eudaimonic motivations for entertainment consumption. Journal of Communication, 61, 984-1004. doi:10.1111/j.1460-2466.2011.01585.x

Park, H. S., Dailey, D, \& Lemus, D. (2002). The use of exploratory factor analysis and principal components analysis in communication research. Human Communication Research, 28, 562-577. doi:10.1111/j.1468-2958.2002.tb00824.x

Raney, A. A. (2004). Expanding disposition theory: Reconsidering character liking, moral evaluations, and enjoyment. Communication Theory, 14, 348-369. doi:10.1111/j.1468-2885.2004.tb00319.x

Raney, A. A. (2006). The psychology of disposition-based theories of media enjoyment. In J. Bryant \& P. Vorderer (Eds.), Psychology of entertainment (pp. 137-150). Mahwah, NJ: Lawrence Erlbaum Associates Publishers.

Raney, A. A., \& Bryant, J. (2002). Moral Judgment and crime drama: An integrated theory of enjoyment. Journal of Communication, 52, 402-415. doi:10.1111/j.1460-2466.2002.tb02552.x

Ryan, R. M., \& Deci, E. L. (2001). On happiness and human potentials: A review of research on hedonic and eudaimonic well-being. Annual Review of Psychology, 52, 141-166. doi:10.1146/annurev.psych.52.1.141 
Sanders, M. S., \& Tsay-Vogel, M. (2016). Beyond heroes and villains: Examining explanatory mechanisms underlying moral disengagement. Mass Communication and Society, 19, 230-252. doi:10.1080/15205436.2015.1096944

Schmeets, H. (2016). De religeuze kaart van Nederland, 2010-2015. Retrieved from: https://www.cbs.nl/-/media/_pdf/2016/51/religie-regionaal-2010-2015.pdf

Shadish, W. R., Cook, T. D., \& Campbell, D. T. (2002). Experimental and quasiexperimental designs for generalized causal inference. Boston, MA: Houghton, Mifflin and Company.

Shafer, D. M., \& Raney, A. A. (2012). Exploring how we enjoy antihero narratives. Journal of Communication, 62, 1028-1046. doi:10.1111/j.14602466.2012.01682.x

Shedlosky-Shoemaker, R., Costabile, K. A., \& Arkin, R. M. (2014). Self-expansion through fictional characters. Self and Identity, 13, 556-578. doi:10.1080/15298868.2014.882269

Slater, M. D., Johnson, B. K., Cohen, J., Comello, M. L. G., \& Ewoldsen, D. R. (2014). Temporarily expanding the boundaries of the self: Motivations for entering the story world and implications for narrative effects. Journal of Communication, 64, 439-455. doi:10.1111/jcom.12100

Social Progress Imperative. (2018). 2018 Social progress index executive summary. Retrieved from: https://www.socialprogress.org/resources?filter=2018

Tamborini, R. (2013). Model of intuitive morality and exemplars. In R. Tamborini (Ed.), Media and the moral mind (pp. 43-74). London, England: Routledge.

Tamborini, R., Eden, A., Bowman, N. D., Grizzard, M., \& Lachlan, K. A. (2012). The 
influence of morality subcultures on the acceptance and appeal of violence. Journal of Communication, 62, 136-157. doi:10.1111/j.1460-2466.2011.01620.x

Tamborini, R., Grall, C., Prabhu, S., Hofer, M., Novotny, E., Hahn, L., Klebig, B., Kryston, K., Baldwin, J., Aley, M., \& Sethi, N. (2018). Using attribution theory to explain the affective dispositions of tireless moral monitors toward narrative characters. Journal of Communication, 68, 842-871. doi:10.1093/joc/jqy049

Tamborini, R., Weber, R., Eden, A., Bowman, N. D., \& Grizzard, M. (2010). Repeated exposure to daytime soap opera and shifts in moral judgment toward social convention. Journal of Broadcasting and Electronic Media, 54, 621-640. doi:10.1111/j.1460-2466.2011.01620.x

The Economist Intelligence Unit. (2019). Democracy Index 2018: Me too?. Retrieved from: https://www.eiu.com/public/topical_report.aspx?campaignid=Democracy2018

Tsay, M., \& Krakowiak, K. M. (2011). The impact of perceived character similarity and identification on moral disengagement. International Journal of Arts and Technology, 4, 102-110. doi:10.1504/IJART.2011.037773

Tsay-Vogel, M., \& Krakowiak, K. M. (2016). Effects of hedonic and eudaimonic motivations on film enjoyment through moral disengagement. Communication Research Reports, 33, 54-60. doi:10.1080/08824096.2015.1117443

van Ommen, M., Daalmans, S., \& Weijers, A. (2014). Who is the doctor in this house?: Analyzing the moral evaluations of medical students and physicians of House, M.D. AJOB Empirical Bioethics, 5, 61-74. doi:10.1080/23294515.2014.938198 Vorderer, P., \& Reinecke, L. (2015). From mood to meaning: The changing model of the 
user in entertainment research. Communication Theory, 25, 447-453. doi:10.1111/comt.12082

Vorderer, P., \& Ritterfeld, U. (2009). Digital games. In R. L. Nabi \& M. B. Oliver (Eds.), The SAGE handbook of media processes and effects (pp. 455-467). Thousand Oaks, CA: SAGE publications, Inc.

Weinmann, C., Roth, F. S., Schneider, F. M., Kramer, T., Hopp, F. R., Bindl, M. J., \& Vorderer, P. (2017). “I don't care about politics, I just like that guy!” Affective disposition and political attributes in information processing of political talk shows. International Journal of Communication, 11, 3118-3140. Retrieved from: https://ijoc.org/index.php/ijoc/article/view/5800/2103

Wirth, W., Hofer, M., \& Schramm, H. (2012). Beyond pleasure: Exploring the eudaimonic entertainment experience. Human Communication Research, 38, 406428. doi:10.1111/j.1468-2958.2012.01434.x

Zillmann, D. (2000). Basal morality in drama appreciation. In I. Bondebjerg (Ed.), Moving images, culture, and the mind (pp. 53-63). Luton, UK: University of Luton Press.

Zillmann, D., \& Bryant, J. (1975). Viewer's moral sanction of retribution in the appreciation of dramatic presentations. Journal of Experimental Social Psychology, 11, 572-582. doi:10.1016/0022-1031(75)90008-6

Zillmann, D., \& Cantor, J. (1972). Directionality of transitory dominance as a communication variable affecting humor appreciation. Journal of Experimental Social Psychology, 11, 572-582. doi:10.1037/h0033384

Zillmann, D., \& Cantor, J. R. (1976). A disposition theory of humor and mirth. In A. J. 
Chapman \& H. C. Foot (Eds.), Humor and laughter: Theory, research, and applications (pp. 93-115). Piscataway, NJ, US: Transaction Publishers.

Zillmann, D., \& Cantor, J. R. (1977). Affective responses to the emotions of a protagonist. Journal of Experimental Social Psychology, 13, 155-165. doi:10.1016/S0022-1031(77)80008-5

Zillmann, D., Taylor, K., \& Lewis, K. (1998). News as nonfiction theater: How dispositions toward the public cast of characters affect reactions. Journal of Broadcasting and Electronic Media, 42, 153-169.

doi:10.1080/08838159809364441 


\section{Appendix A}

\section{Character Type Descriptions}

The following are the seven character type descriptions used by Eden et al. (2017), originally adapted from TV Tropes

(http://www.tvtropes.org/pmwiki.php/Analysis/AntiHero). In the study, each participant will be randomly assigned one of the seven tropes and base their response on a character who they identify as an example of that trope. See appendix B for the complete questionnaire.

Hero. This type of character is a character who is always right, selflessly fights for noble causes, is kind to all and is a natural and charismatic leader. He successfully fights against evil, saves those in distress and always reaches his predefined goals. Examples of this type of character are: Luke Skywalker from Star Wars and Superman.

Cynical (Disney) anti-hero. This type of character has heroic intentions but often have a sour, cynical view of the world. This type of character stands a good chance of positive transformation over the course of the story, once they confront their internal conflicts, or find someone or something they want to fight for. Examples of this type of character are: Shrek and Tyrion Lannister from Game of Thrones.

Pragmatic anti-hero. This type of character is willing to do immoral things for a good cause. In their view, the end justify (the where necessary violent) means. The intentions of these characters are pure and good and the abide by a strict personal moral code, which they follow in reaching their goals. Examples of this type of character are: Katniss Everdeen from The Hunger Games and Batman.

Classical anti-hero. This type of character is full of self-doubt, mediocre (or 
worse) in combat, has trouble seeing the whole picture, unsuccessful in love, frightened, cowardly and/or not particularly bright. He or she tends to "grow" over the course of the narrative and overcomes his or her own weaknesses. Examples of this type of character are: Elsa from the movie Frozen and Spiderman.

Unscrupulous hero. This type of character will fight for the good cause out of good intentions. However, they are unaffected by the collateral effects and damages they create along the way. They live according to a code, are often violent (in pursuit of justice and vengeance), are cynical (due to personal trauma) as well as opportunistic. Examples of this type of character are: Jack Bauer from 24 and Mad Max from the similarly-titled movies.

Nominal hero. Even though this type of character fights on the side of good, their intentions/motivations are anything but pure or good (often focused on selfish goals). This type of character is often seen through the lens of the enemy of my enemy - the lesser of two evils. Examples of this type of character are: Dexter Morgan (from Dexter the TV-show) and Loki from the Marvel universe (Thor, The Avengers).

Villain. This type of character is the one that works against the good guys, is characterized and even admired for his or her determination in being evil, having selfish goals, cunning and intelligence. Nevertheless this character almost never reaches his or her goal, is almost always beaten or vanquished and fails in his or her evil intentions. Examples of this type of character are: Sauron (from Lord of the Rings) and Darth Vader from Star Wars. 


\section{Appendix B}

Below is the survey instrument (from Qualtrics) used in the present study.

\section{Start of Block: Cover Letter}

Dear Participant,

This letter is a request for you to take part in a research project to explore perceptions of characters in popular entertainment research. This project is being conducted by Dr. Nick Bowman and Koji Yoshimura, in the Department of Communication Studies at West Virginia University. Your participation in this project is greatly appreciated and it will take approximately 20 minutes to complete the attached survey.

Your involvement in this project will be kept as confidential as legally possible. All data will be reported in aggregate. You must be 18 years of age or older to participate. Your participation is completely voluntary. You may skip any question that you do not wish to answer and you may discontinue at any time. Your class standing will not be affected if you decide either not to participate or to withdraw. West Virginia University's Institutional Review Board acknowledgement of this project is on file (protocol \#1902465860).

Participation in this research project involves completing one survey consisting of both closed and open-ended responses. If you choose to participate, we would strongly suggest that the survey be completed on a desktop or laptop computer, or some other device with a functional keyboard. Using a mobile phone or tablet computer might cause some of the survey questions to display in an odd manner, and you'll be asked at times to respond to open-ended questions where you'll need to type or enter in text-based answers. There are no known or expected risks from participating in this study.

Participants in this study have the opportunity to be entered into a drawing for one of four \$25 Amazon gift cards. Students enrolled in certain WVU COMM courses may also be eligible to receive research credit (extra credit) toward that course. Please consult your syllabus and/or contact your instructor, to find out if you are eligible. Other options are available to earn the same extra credit without participating in this research.

I hope that you will participate in this research, as it will be beneficial to understanding how media consumers perceive and interpret characters. Thank you very much for your time. Should you have any questions about this letter or the research project, please feel free to contact Koji Yoshimura atky0018@mix.wvu.edu.

Sincerely,

Nick Bowman, Ph.D.

Principal Investigator

nicholas.bowman@mail.wvu.edu

Koji Yoshimura

Co-Investigator

ky0018@mix.wvu.edu

If you'd like to participate in this study, please click the "Next Page" button. If you are 
no longer interested in participating, simply close your browser window at this time.

Please verify that you're a human.

[Captcha request]

\section{End of Block: Cover Letter}

\section{Start of Block: Introduction}

Thank you very much for participating in our research on perceptions of fictional characters in media. The questions in this survey should be easy to answer, and please be aware that there are no "right" or "wrong" answers. Your answers are kept confidential, so please feel free to respond honestly. Honesty is very important to our research because we want to know what people really think and believe.

This survey will consist of three broad sets of questions. The first part will ask about your media use habits and preferences, and about your general views on morality. The second part of the survey will ask for your thoughts about a specific character in film or television. The third part of the survey will briefly ask you for some information about yourself. As a reminder, we expect this to take no longer than 20 minutes.

Please click "Next Page" to continue the survey.

\section{End of Block: Introduction}

\section{Start of Block: Part 1: Media Use and Preferences}

We would like to begin by asking you some questions about your general media habits and preferences.

For each day of an average week, how much time do you spend watching television? Please type your answer in hours, below (you may indicate fractions of an hour using decimal points; e.g., 90 minutes $=1.5$ hours). This would include any forms of TV, including streaming and other devices.

Sunday (1) 
Monday (2)

Tuesday (3)

Wednesday (4)

Thursday (5)

Friday (6)

Saturday (7)

About how many films do you watch in an average month? Please type your answer in whole numbers.

Please rate the following items on a scale ranging from "Strongly disagree" to "Strongly agree".

\begin{tabular}{|c|c|c|c|c|c|}
\hline & $\begin{array}{c}\text { Strongly } \\
\text { Disagree (1) }\end{array}$ & Disagree (2) & $\begin{array}{c}\text { Neither } \\
\text { Disagree } \\
\text { nor agree } \\
\text { (3) }\end{array}$ & Agree (4) & $\begin{array}{l}\text { Strongly } \\
\text { Agree (5) }\end{array}$ \\
\hline $\begin{array}{l}\text { I prefer to } \\
\text { watch news } \\
\text { and } \\
\text { information } \\
\text { content. (1) }\end{array}$ & & & & & \\
\hline $\begin{array}{l}\text { I prefer to } \\
\text { watch } \\
\text { entertainment } \\
\text { content. (2) }\end{array}$ & 7 & & & & \\
\hline $\begin{array}{l}\text { I prefer to } \\
\text { watch } \\
\text { fictional } \\
\text { content. (3) }\end{array}$ & $\cap$ & & & 6 & \\
\hline
\end{tabular}


The following questions will help us get a sense of how you tend to view morality, both in general and in relation to media.

Please respond to the following items on a scale from "not at all relevant" to "extremely relevant". When you decide whether something is good or bad, to what extent are the following considerations important for your judgment:

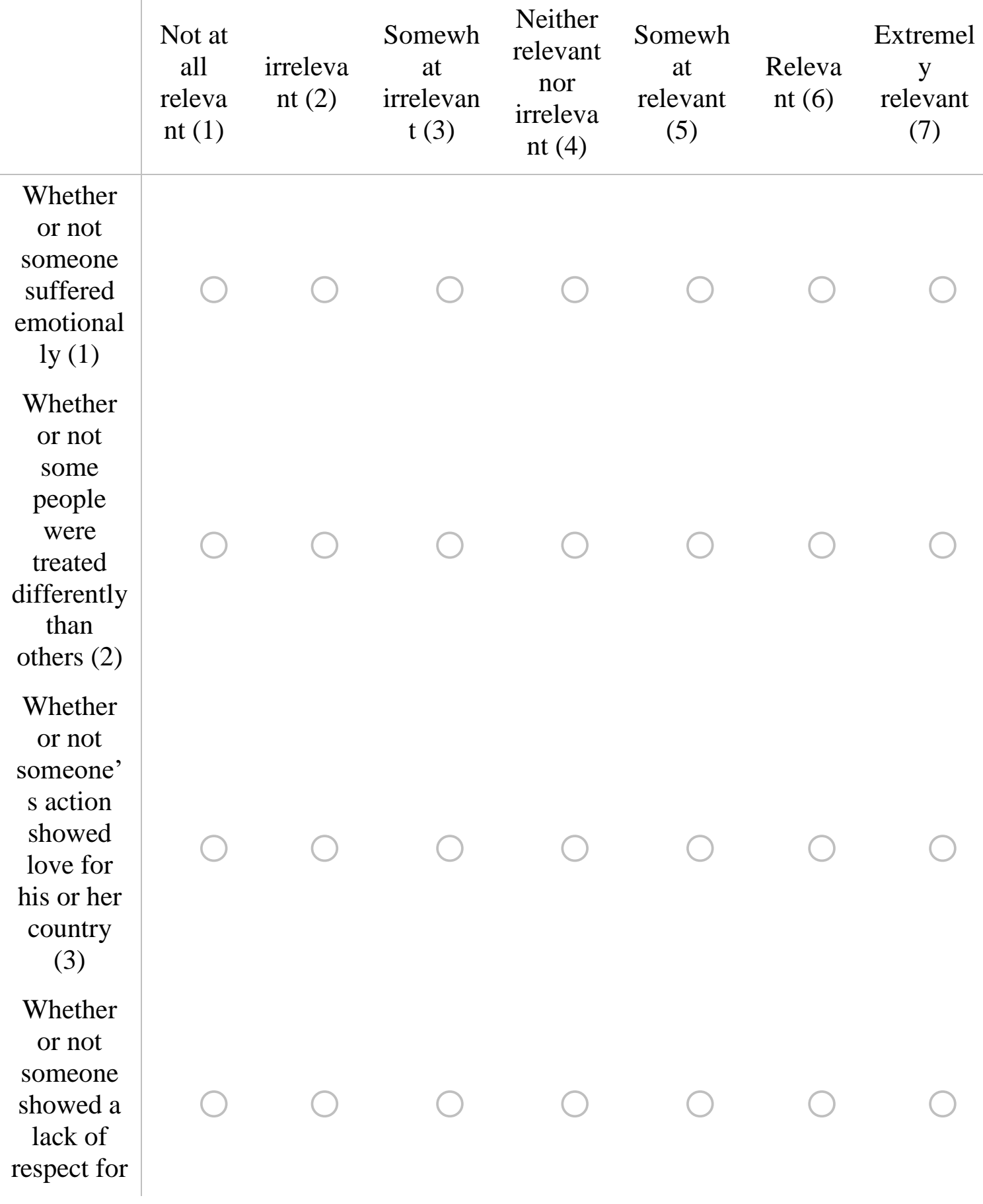


authority

Whether or not someone violated standards of purity and decency

Whether or not someone was good at math

Whether or not someone cared for someone weak or vulnerable (7)

Whether or not someone acted unfairly

Whether or not someone did something to betray his or her group (9)

Whether or not someone 


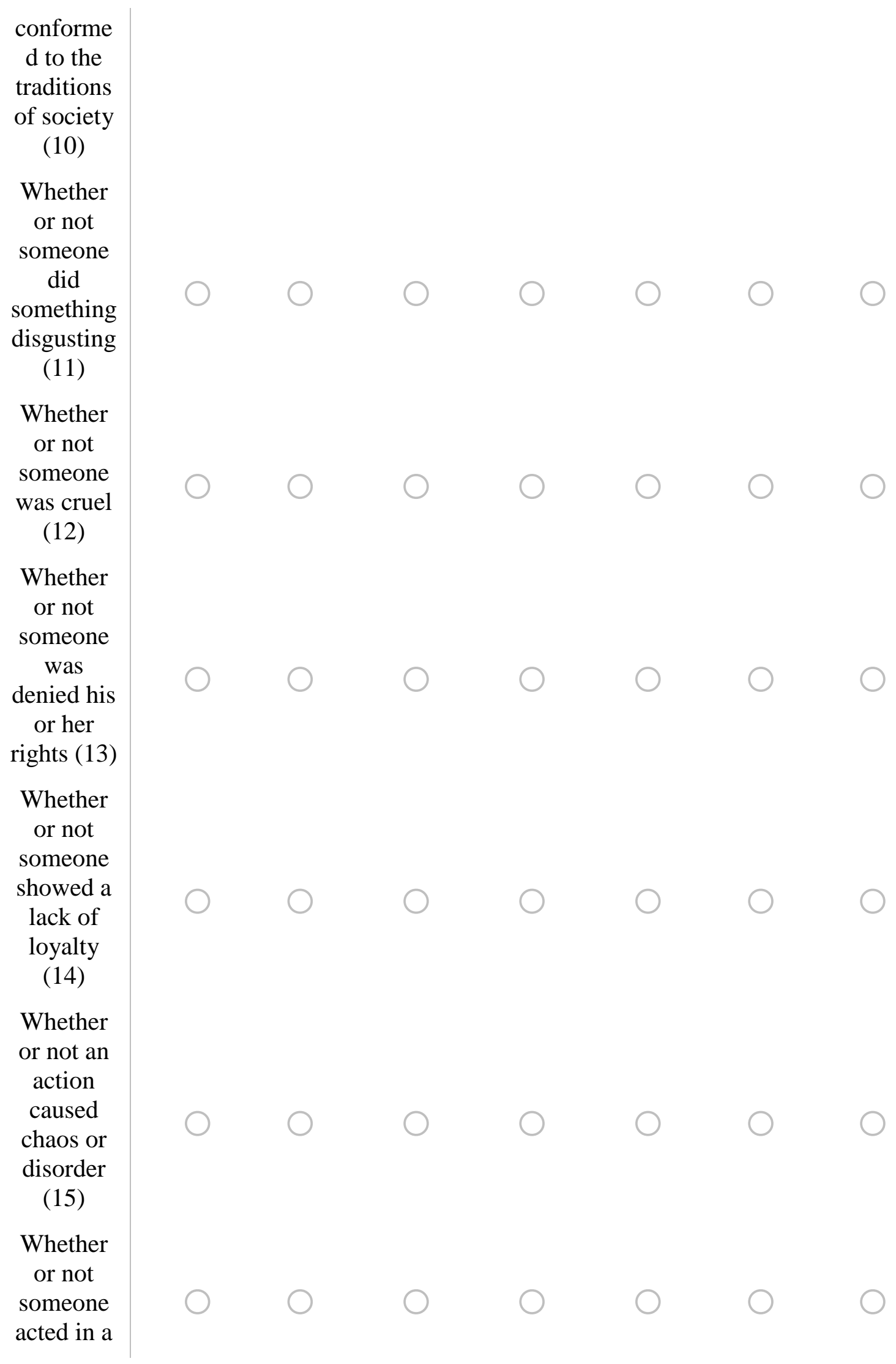


way that

God

would

approve

of (16)

The following statements are about film and television characters. For each statement, indicate to what extent you agree with it, on a scale ranging from "totally disagree" to "totally agree".

\begin{tabular}{|c|c|c|c|c|c|c|}
\hline $\begin{array}{c}\text { Totally } \\
\text { disagre } \\
\text { e (1) }\end{array}$ & $\begin{array}{c}\text { Disagre } \\
\text { e (2) }\end{array}$ & $\begin{array}{c}\text { Slightly } \\
\text { disagre } \\
\text { e (3) }\end{array}$ & $\begin{array}{l}\text { Neither } \\
\text { agree } \\
\text { nor } \\
\text { disagre } \\
\text { e (4) }\end{array}$ & $\begin{array}{c}\text { Slightl } \\
\text { y agree } \\
(5)\end{array}$ & $\begin{array}{l}\text { Agre } \\
\text { e (6) }\end{array}$ & $\begin{array}{c}\text { Totall } \\
\text { y } \\
\text { agree } \\
(7)\end{array}$ \\
\hline
\end{tabular}

A film
hero who
murdered
murderers lets
justice prevail
without the
limitations of the
law. (1)
When a
TV villain
murdered the
hero, it is still not
justified for the
hero to kill the
villain. (2)
On TV,
hostage takers
always have the
intention to kill
the hostages, so
the hero should
always try to kill
the hostage taker.
(3)
On TV, it




\begin{abstract}
who kill drug
dealers serve a service to

society. (4)

Sometime

$\mathrm{s}$ it is acceptable in a film if a government agency (like the CIA) decides to kill a foreign state leader if that leader helps terrorists. (5)

A film

hero is justified in using deadly force if the villain is a killer.

(6)

A TV
agent who kills
serial killers
creates real
justice. (7)
A film
hero is justified
in using deadly
force if the
villain is a rapist.
\end{abstract}

(8)

\section{End of Block: Part 1: Media Use and Preferences}

\section{Start of Block: Part 2: [Character trope]}

Questions in this section will ask about your thoughts on a character from media. Please think about a film or television character that you think is a good example of the character description below.

[Randomly assigned trope description here] 
The name of this character is:

\section{Page Break}

The movie or TV show in which [character] is featured:

What is [character]'s gender?

What do you estimate is the age of [character]?

Why do you think [character] fits the description? Please provide a brief explanation in 3 to 6 sentences. 
If there are multiple iterations of [character] (such as in different movies, TV series, books, etc.), is there a particular version of them you are thinking of? If so, which?

How familiar would you say you are with [character]?

$\boldsymbol{\nabla}$ Not familiar at all (5) ... Extremely familiar (5)

Now, please indicate to what extent to which [character] possesses the following characteristics on a scale ranging from "totally disagree" to "totally agree":

\begin{tabular}{|c|c|c|c|c|c|}
\hline & $\begin{array}{l}\text { Totally } \\
\text { disagree } \\
\text { (1) }\end{array}$ & $\begin{array}{l}\text { Disagree } \\
\text { (2) }\end{array}$ & $\begin{array}{l}\text { Neither } \\
\text { disagree } \\
\text { nor agree } \\
\quad(3)\end{array}$ & Agree (4) & $\begin{array}{c}\text { Totally } \\
\text { agree (5) }\end{array}$ \\
\hline Tolerant (1) & & & & & \\
\hline Friendly (2) & & & & & \\
\hline Warm (3) & & & & & \\
\hline Polite (4) & & & & & \\
\hline Soft-hearted (5) & & & & & \\
\hline Intelligent (6) & & & & & \\
\hline $\begin{array}{c}\text { Smart/Resourceful } \\
\text { (7) }\end{array}$ & & & & & \\
\hline Dumb/Foolish (8) & & & & & \\
\hline Crazy (9) & & & & & \\
\hline
\end{tabular}




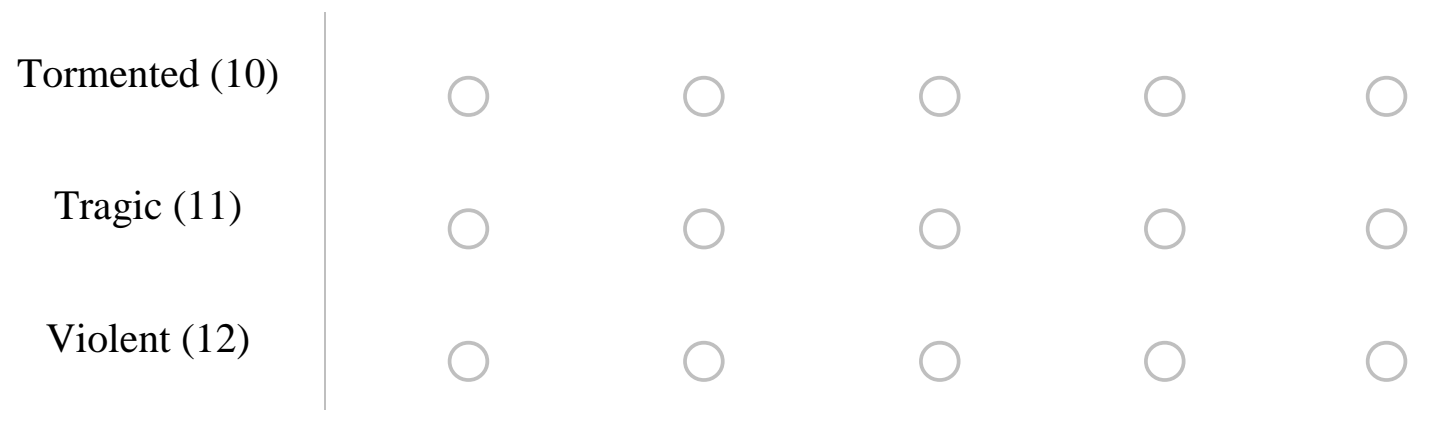

With [character] in mind, please indicate the extent to which you agree with the following statements on a scale from "strongly disagree" to "strongly agree".

$\begin{array}{ccccccc}\text { Strongly } & \text { Disagree } & \begin{array}{c}\text { Slightly } \\ \text { disagree }\end{array} & \begin{array}{c}\text { Neither } \\ \text { agree } \\ \text { disagree }\end{array} & \begin{array}{c}\text { Slightly } \\ \text { agree }\end{array} & \begin{array}{c}\text { Agree } \\ \text { disagree }\end{array} & \begin{array}{c}\text { Strongly } \\ \text { agree }\end{array} \\ (1) & (2) & (3) & (6) & \text { (7) }\end{array}$

The
character
seems like
they would
cause
someone to
suffer
emotionally.
(1)
The
character
seems like
they would
be cruel. (2)
The
character
seems like
they would
murder
someone.
(3)
The
character


seems like
they would
physically
hurt another
person. (4)
The
character
seems like
they would
treat some
people
differently
than others.

(5)

The character seems like they would act unfairly.

The character seems like they would deny others their rights.

The character seems like they would treat people equally. (8)

The character seems like they would betray his or her group.

(9)

The character 
seems like they would show a lack of loyalty.

The character seems like they would be loyal to his or her friends. (11)

The character seems like they would be twofaced. (12)

The character seems like they would show a lack of respect for authority. (13)

The character seems like they would cause chaos or disorder.

(14)

The character seems like they would disobey orders from a superior. (15) 


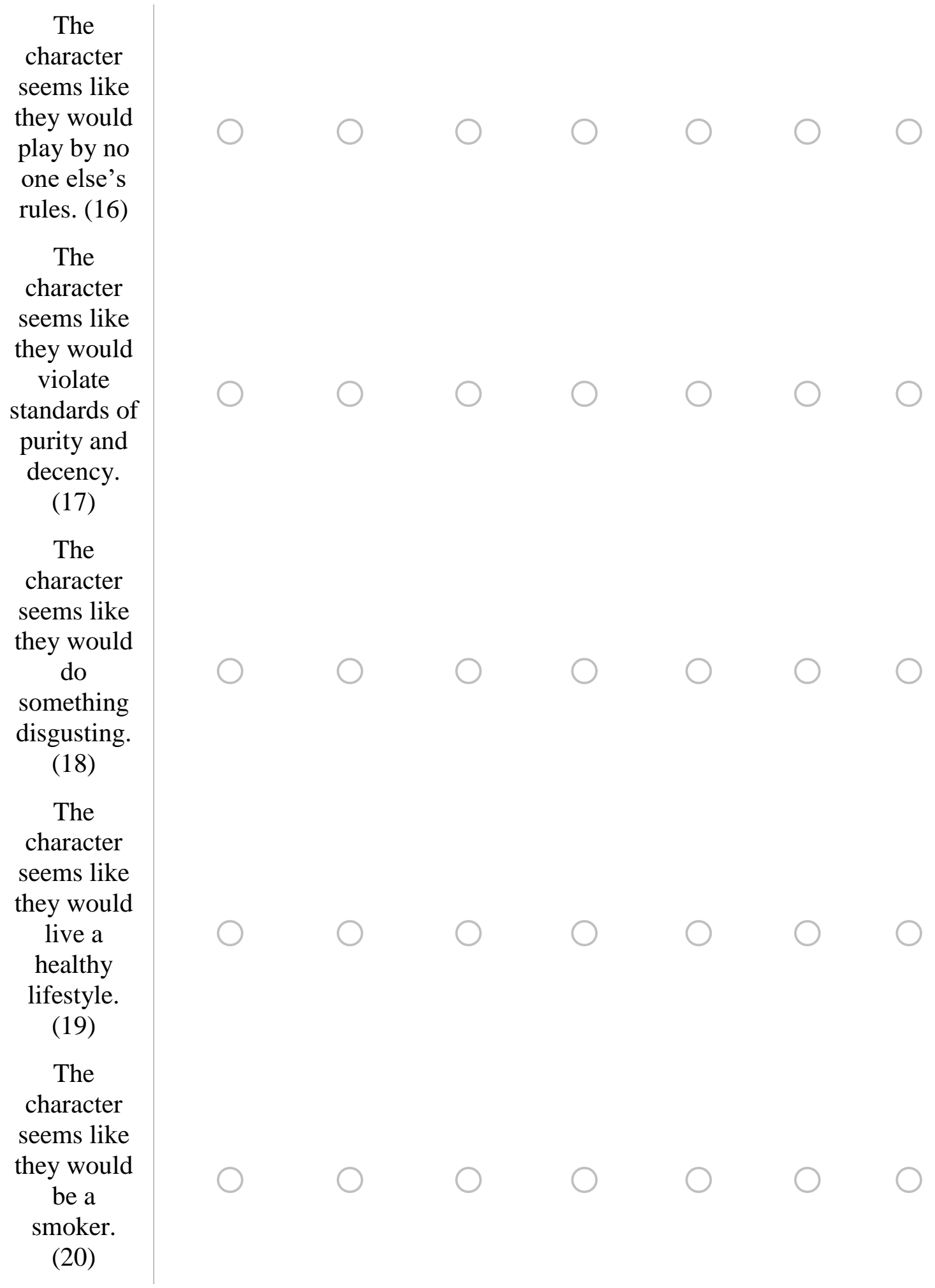




\section{Page Break}

The questions below will ask about your personal experiences as a viewer of your chosen character.

Please answer the following questions on a scale ranging from "not at all" to "very much". Thinking of [character], please respond to the following questions:

\begin{tabular}{|c|c|c|c|c|c|}
\hline Not a & $\begin{array}{c}\text { A } \\
\text { little } \\
(2)\end{array}$ & $\begin{array}{l}\text { Slightly } \\
\text { (3) }\end{array}$ & $\begin{array}{l}\text { Somewhat } \\
\text { (4) }\end{array}$ & $\begin{array}{c}\text { Moderately } \\
\text { (5) }\end{array}$ & $\begin{array}{l}\text { A lot } \\
(6)\end{array}$ \\
\hline
\end{tabular}

To what
extent has
watching
this
character
resulted in
your having
new
experiences?

(1)

When you

look at this character, are you more aware of the things around you?

(2)

To what extent does the character increase your ability to achieve new things?

(3)

To what extent does looking at this character make you 
attractive to
other
people? (4)

To what extent does this character help you better understand who you are? (5)

To what extent do you see the character as a way to improve your own skills? (6)

Did you often feel that you were learning new things about the character?

(7)

To what extent is the character a source of exciting experiences?

To what extent do the benefits of the character (skills, personality) compensate 


for your
own
weaknesses?
(9)
To what
extent do
you feel that
the character
has given
you a
broader
view of
reality? (10)
To what
extent did
the character
ensure that
you learned
new things?

(11)

To what extent have you become a better person by looking at this character? (12)

To what extent did looking at this character ensure that you have more respect for the people around you? (13)

To what extent did 
looking at

this

character

raise your

level of

knowledge?

(14)

Thinking about your chosen character, please select the figure below which best represents how much you and the character conform. In the graphic below, one circle represents you, and one $(\mathrm{X})$ represents [character].

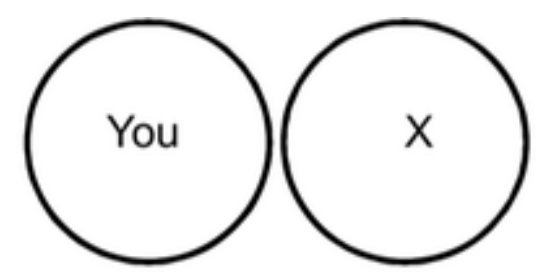

1

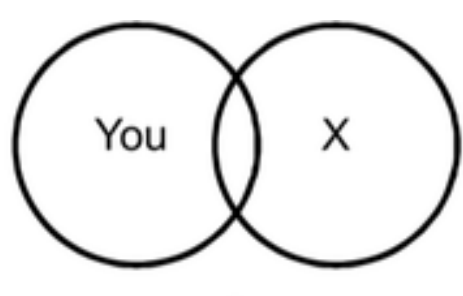

2

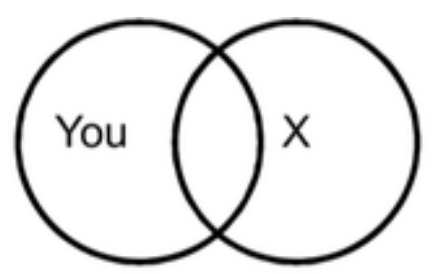

3

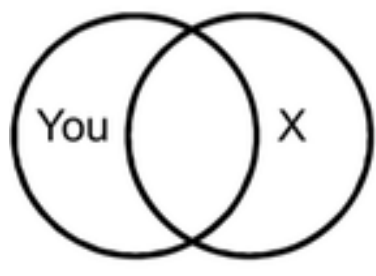

4

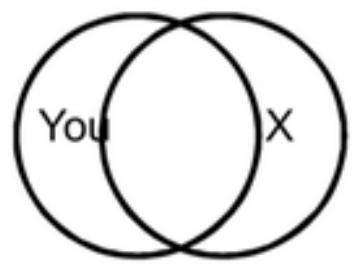

5

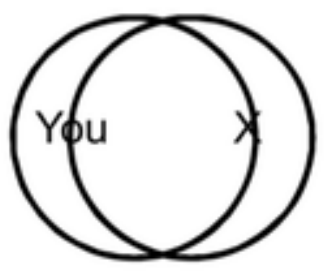

6
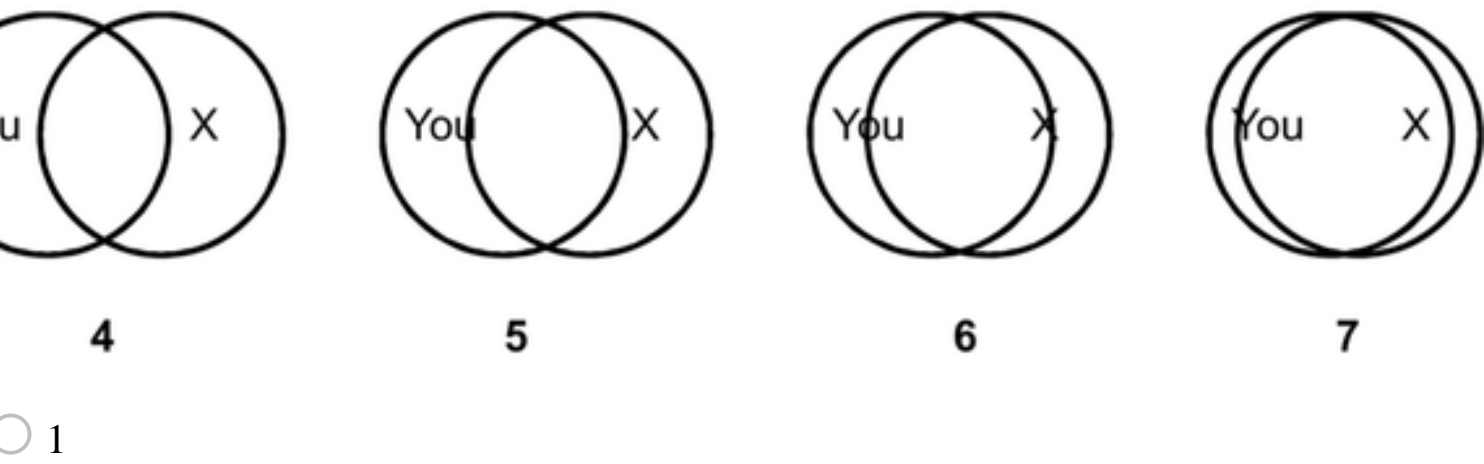

2

3

4

5

6 
Please respond to the following items on a scale ranging from "strongly disagree" to "strongly agree". Thinking about [character], indicate the extent to which you agree or disagree with the following statements:

\begin{tabular}{|c|c|c|c|c|c|c|c|}
\hline & $\begin{array}{l}\text { Strongly } \\
\text { disagree } \\
\text { (1) }\end{array}$ & $\begin{array}{c}\text { Disagree } \\
\text { (2) }\end{array}$ & $\begin{array}{l}\text { Slightly } \\
\text { disagree } \\
\text { (3) }\end{array}$ & $\begin{array}{l}\text { Neither } \\
\text { agree } \\
\text { nor } \\
\text { disagree } \\
\quad(4)\end{array}$ & $\begin{array}{l}\text { Slightly } \\
\text { agree } \\
\text { (5) }\end{array}$ & $\begin{array}{l}\text { Agree } \\
\text { (6) }\end{array}$ & $\begin{array}{c}\text { Strongly } \\
\text { Agree } \\
\text { (7) }\end{array}$ \\
\hline $\begin{array}{l}\text { The } \\
\text { character } \\
\text { is the sort } \\
\text { of person I } \\
\text { want to be } \\
\text { like } \\
\text { myself. (1) }\end{array}$ & 0 & 0 & $\bigcirc$ & 0 & 0 & 0 & 0 \\
\hline $\begin{array}{l}\text { Sometimes } \\
\text { I wish I } \\
\text { could be } \\
\text { more like } \\
\text { the } \\
\text { character. } \\
\text { (2) }\end{array}$ & $\bigcirc$ & 0 & 0 & 0 & 0 & 0 & 0 \\
\hline $\begin{array}{l}\text { I'd like to } \\
\text { do the } \\
\text { kinds of } \\
\text { things the } \\
\text { character } \\
\text { does. (3) }\end{array}$ & 0 & 0 & 0 & 0 & 0 & 0 & 0 \\
\hline $\begin{array}{l}\text { The } \\
\text { character } \\
\text { has the } \\
\text { same } \\
\text { attitudes } \\
\text { as I do. (4) }\end{array}$ & 0 & 0 & 0 & 0 & 0 & 0 & 0 \\
\hline $\begin{array}{l}\text { The } \\
\text { character } \\
\text { has the }\end{array}$ & 0 & 0 & 0 & 0 & 0 & 0 & 0 \\
\hline
\end{tabular}




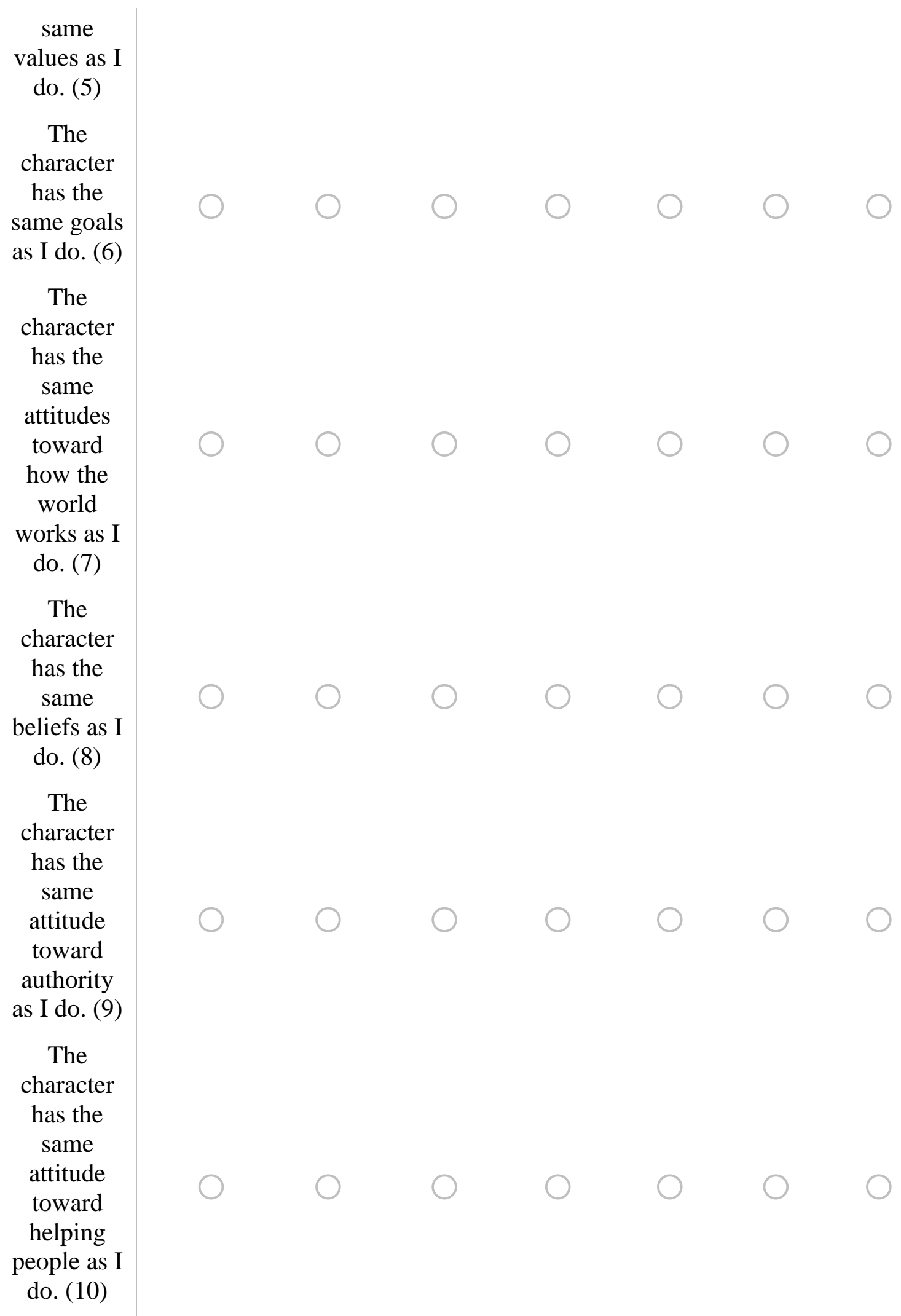


Please respond to the following items on a scale ranging from "strongly disagree" to "strongly agree". Thinking of [character], answer the extent to which you agree with the following statements:

\begin{tabular}{|ccccccc} 
Strongly & Neither \\
Disagree & Disagree & Slightly & agree & Slightly & Agree & Strongly \\
disagree & nor & agree & agree \\
$(1)$ & $(2)$ & $(3)$ & disagree & $(5)$ & $(6)$ & $(7)$ \\
& & & $(4)$ & & &
\end{tabular}

I like to

look at this

character.

(1)

I find it fun

to watch

this

character.

(2)

This

character is

entertaining.

(3)

This

character is

meaningful

to me. (4)

I am

emotionally

touched by

this

character.

(5)

This

character

made me

think. (6)

I will think

of this

character

for a long 


\begin{abstract}
time. (7)
I will never

forget this

character.

(8)

This

character

has made a

lasting

impression

on me. (9)

This

character is

like me.

(10)

This

character is

like who I

want to be.
\end{abstract}

(11)

\title{
End of Block: Part 2: Hero
}

\section{Start of Block: Part 3: About You}

As we wrap up our survey, we'd like to ask you a few very quick questions about yourself. These questions are of course voluntary, but answering them gives us a broad sense of the people participating in our research.

What is your age?

What is your gender? 
Start of Block: Wrapping Up

Thank you very much for participating in this research on perceptions of fictional character types.

To be entered into the drawing for one of four $\$ 25$ gift cards, please enter your email below. If you would like to receive credit in a COMM course for completing this survey, please use your WVU .mix email address. All information we gather from you will be kept confidential.

If you have any questions about the study, please feel free to email co-investigator Koji Yoshimura at ky0018@mix.wvu.edu.

Email address:

Do you intend to earn extra credit in a WVU COMM course by participating in this research study? If you select yes, we will contact you at the email address you provided with further instructions on how to claim extra credit for participating in this research.

Yes (1)

No (2) 